RUNNING HEAD: Self-control and autonomous motivation

\title{
Self-Control and the Reasons Behind Our Goals
}

\author{
Benjamin A. Converse and Lindsay Juarez \\ University of Virginia \\ Marie Hennecke \\ University of Zurich
}

○ 2018, American Psychological Association. This paper is not the copy of record and may not exactly replicate the final, authoritative version of the article. Please do not copy or cite without author permission. The final article will be available, upon publication, via its DOI: 10.1037/pspp0000188

Acknowledgements:

The first two authors contributed equally and are listed in alphabetical order. Studies 2, 3 and 4P were conducted as part of Lindsay Juarez's doctoral dissertation. We are grateful to committee members Christopher Hulleman, Sophie Trawalter, and Timothy Wilson for their helpful comments. We are grateful for generous funding from the John Templeton Foundation awarded to Benjamin Converse through the New Paths to Purpose Network at Chicago Booth Center for Decision Research and from the Swiss National Science Foundation awarded to Marie Hennecke and Veronika Brandstätter (Grant \#100019_156516).

To whom correspondence should be addressed:

Benjamin A. Converse, Frank Batten School of Leadership and Public Policy, University of Virginia, 235 McCormick Road, PO Box 400893, Charlottesville, VA 22904.

Email:converse@ virginia.edu

Phone: 434.243 .3730

Open Science Framework: https://osf.io/ydgur/ 


\begin{abstract}
Motivation derived from a sense of truly valuing or enjoying one's pursuits ("wanting to do it") as opposed to motivation born of external demands or other people's expectations ("having to do it") - is associated with goal-pursuit success and overall well-being. But what determines the quality of motivation in the first place? Many theoretical perspectives identify features of the task or situation as determinants, but have largely ignored the potential contribution of individual self-regulatory tendencies. We ask here whether individual differences in self-control may be associated with an individual's likelihood of "wanting to" pursue current goals, operationalized as the momentary experience of autonomous motivation. We first describe an exploratory experience-sampling study that documented the association (Study 1) and prompted subsequent development of the hypothesis that trait self-control and autonomous motivation are related. A second experience sampling study replicated the effect (Study 1R) and two cross-sectional studies helped hone its interpretation (Studies 2 and 3). We then employed an experimental paradigm to test whether the association between trait self-control and autonomous motivation is goal-dependent. Consistent with an instrumental, self-regulatory account of the association, we found that trait self-control was related to autonomous motivation for a novel task only when an individual expected to continue working on that task (Study 4). Employing an integrative perspective, this work expands our understanding of trait self-control by identifying it as a candidate contributor to motivation quality, and, more generally, helps to integrate otherwise disparate approaches to understanding motivation.
\end{abstract}

Key words: self-control, goals, motivation, autonomy, self-determination 
Great teachers, inspirational coaches, wise grandparents, and motivational theorists agree that successful goal pursuit is not just about what you are pursuing and how, but also why you are pursuing it. From moment to moment, people may work just as hard when they "have to" as when they "want to," but these opposing kinds (or qualities) of motivation prompt different modes of regulation, leading to different outcomes in the long run (Deci \& Ryan, 2000). In other words, the intensity of motivation may be at equally high levels, but if different reasons underlie that motivation, then it takes on a different quality. For example, if two students are spending long hours studying for the same exam, one because she enjoys the material and the other because she wants to make Dean's List, both might be highly motivated in a study session, but the first student is more likely to flourish over the course of the semester. Similarly, if two professionals are grinding out an important project, one because he cares deeply about the work and the other because he wants to impress the boss, both might be highly motivated during the project period, but the first is more likely to thrive in the job. Indeed, motivation derived from a sense of truly valuing or enjoying one's pursuits ("wanting to do it") - as opposed to motivation born of external demands or other people's expectations ("having to do it") - is associated with increased progress, perseverance, success, and well-being (Judge, Bono, Erez, \& Locke, 2005; Milyavskaya, Inzlicht, Hope, \& Koestner, 2015; Sheldon \& Elliot, 1998, 1999; Sheldon \& Houser-Marko, 2001; Vansteenkiste, Mouratidis, \& Lens, 2010; Yeager et al., 2014).

Given that the reasons underlying motivation so profoundly affect goal pursuit, it seems paramount to understand what determines those reasons in the first place. In the current work, we explore a person's own self-regulatory tendencies as one potential determinant. Typically, research has attributed the quality of motivation to the goals people choose to pursue (Sheldon \& Elliot, 1999) to specific task features, such as novelty and challenge (Csikzentmihalyi, 1975; 
Danner \& Lonky, 1981; Deci, 1975), or to situational features, such as freedom of choice and level of surveillance (Deci, Eghari, Patrick, \& Leone, 1994; Harackiewicz, Manderlink, \& Sansone, 1984; Lepper \& Greene, 1975). As a first step to determining whether individuals’ own self-regulatory tendencies might play a role in determining the quality of their motivation, the current work tests whether there is an association between trait self-control (Tangney, Baumeister, \& Boone, 2004) and the momentary experience of autonomous motivation (Deci \& Ryan, 2000; Milyavskaya et al., 2015; Sheldon \& Elliot, 1998); and it further examines the conditions under which such an association might manifest. Using experience-sampling and cross-sectional paradigms, we tested for the association in everyday goals at work and home. We then employed an experimental paradigm to explore whether the association is responsive to goal activation, which would suggest an instrumental relation between the two.

\section{Reasons Matter: Understanding the 'Why'}

Our central question is whether, and under what conditions, there is an association between the tendency to successfully exert self-control and the tendency to feel that one is pursuing current goals because one "wants to." We ground this idea of "wanting to" rather than "having to" in conceptualizations specified by self-determination theory (SDT) and elaborated in the self-concordance model (Deci \& Ryan, 1985, 2000; cf. deCharms, 1968; Harackiewicz \& Sansone, 1991; Milyavskaya et al., 2015; Milyavskaya, Nadolny, \& Koestner, 2014; Sheldon \& Elliot, 1998). SDT refers to underlying reasons as the "why" of goal pursuit, and describes the behaviors that follow on a spectrum of self-determination (Howard, Gagné, \& Bureau, 2017). ${ }^{1}$

The most self-determined behaviors are those that are intrinsically motivated. These behaviors are pursued out of interest and enjoyment. In contrast, less self-determined behaviors can follow from various forms of extrinsic motivation, further differentiated by their degree of 
relative autonomy. The least autonomous, most controlled form of regulation is external. Goal pursuit is externally regulated when the main reason for pursuit is receiving rewards or avoiding punishments from others. A more autonomous, less controlled form of regulation is introjection. Goal pursuit is regulated via introjection when the individual self-administers his or her own rewards and punishments, often in the form of contingent self-worth or the threat of guilt and shame. Finally, an even more autonomous, less controlled form of regulation is identification. Goal pursuit is regulated via identification when people come to accept the underlying value of an external reward and accept its pursuit as identity-consistent. For example, if one engages in unpleasant tasks to help disadvantaged others, this might be an identified pursuit. The work may not be inherently enjoyable, but the outcome is one that the person truly finds meaningful and valuable and the process thus resembles that of intrinsic regulation.

Given conceptual similarity and regular empirical overlap, intrinsic and identified regulation processes are often referred to collectively as autonomous motivation. Autonomously motivated behaviors involve the experience of volition (Deci \& Ryan, 2000), are concordant with personal values (Sheldon \& Elliot, 1998, 1999), and tend to reflect what people "want to" do (Milyavskaya et al., 2014, 2015). Autonomous motivation produces behaviors that feel relatively self-determined. Similarly, introjected and external regulation processes are often referred to collectively as controlled motivation. Behaviors stemming from controlled motivation involve the experience of coercion, do not feel authentic, and tend to reflect what people "have to" do. Controlled motivation produces behaviors that feel relatively less self-determined. Though many early SDT studies aggregated autonomous and controlled motivations into a single bipolar index of self-concordance, we heed recent calls to examine them separately (Koestner, Otis, Powers, Pelletier, \& Gagnon, 2008). 


\section{Divergent Outcomes}

It is important to understand potential contributors to motivation quality because, while motivation can be high in either case, the different regulatory processes prompt divergent outcomes. Intrinsic motivation is energizing in its own right (Nix, Ryan, Manly, \& Deci, 1999; Ryan \& Frederick, 1997) and proceeding with a sense of authentic purpose sustains motivation and well-being even in uninspiring circumstances (Bundick, 2011; Sheldon \& Houser-Marko, 2001; Yeager \& Bundick, 2009; Yeager et al., 2014). At this point, hundreds of studies have demonstrated that pursuing activities for relatively more self-determined reasons is associated with success and well-being (Deci \& Ryan, 2012). In the context of education alone, autonomous motivation is associated with deeper information processing, more creativity, less drop-out, and enhanced well-being (Black \& Deci, 2000; Boggiano, Flink, Shields, Seelback, \& Barrett, 1993; Grolnick \& Ryan, 1987; Koestner, Ryan, Bernieri, \& Holt, 1984; Vansteenkiste, Simons, Lens, Sheldon, \& Deci, 2004; for a review, see Reeve, Deci, \& Ryan, 2004). Similarly beneficial outcomes have been identified for physical health (Ng et al., 2012), mental health (Ryan, Deci, \& Vansteenkiste, 2016), sustainable behavior (Unsworth \& McNeill, 2017), and work motivation (Deci, Connell, \& Ryan, 1989; Gagne \& Deci, 2005).

The benefits of autonomous motivation also persist beyond focal-goal completion. When people pursue goals for autonomous reasons, they tend to exhibit sustained commitment and enhanced well-being after focal-goal attainment (Erdvik, Øverby, \& Haugen, 2014; Sheldon \& Elliot, 1999; Sheldon, Ryan, Deci, \& Kasser, 2004). In self-control dilemmas, if people view a depleting task as "an opportunity for fun" rather than "an obligation to work," they feel more vitalized by goal completion and are more likely to exercise self-control in a subsequent dilemma (Laran \& Janiszewski, 2010). In contrast, when people pursue goals for controlled reasons, they 
often exhibit decrements in subsequent motivation and interest (Bénabóu \& Tirole, 2003; Deci, Koestner, \& Ryan, 1999; Wrzesniewski et al., 2014).

\section{Lesser Known Origins}

Though copious research has examined the consequences (or at least correlates) of selfdetermination, less attention has been directed to identifying antecedents. Individual differences in the propensity to adopt autonomously motivated goals have been established (Deci \& Ryan, 1985; Weinstein, Pryzbylski, \& Ryan, 2012), but such differences have not been explained in terms of other processes. The few investigations designed to examine antecedents have chiefly considered features of the goal, such as its purpose or alignment with one's values (e.g., Ryan, 1995; Milyavskaya et al., 2014; Sheldon \& Elliot, 1999); or aspects of the environment that are supportive of authenticity and autonomy, such as agency or freedom (e.g., Gagné \& Deci, 2005; Harackiewicz \& Elliot, 1998; Williams \& Deci, 1996). Additionally, a few studies have taken a developmental approach, linking self-determination to the style of one's early parental interactions (Soenens \& Vansteenkiste, 2005; Vallerand, Fortier, \& Guay, 1997). In this project, we turn the focus to self-control as a potential determinant of motivation quality. Evidence of an association between these two variables would be a necessary (but not sufficient) precondition for the theoretical claim that they are causally linked.

\section{A Link Between Self-Control and Motivational Quality?}

Self-control is often crucial for protecting long-term goals from short-term temptations (Ainslie, 1992; Baumeister, Heatherton, \& Tice, 1994; Loewenstein, 1996; Mectalfe \& Mischel, 1999; Thaler \& Shefrin, 1981). For example, for some people, maintaining a healthy heart might involve abstaining from french fries, being in a satisfying relationship might involve deescalating conflicts, and achieving academic success might involve turning down party 
invitations. What counts as (exercising) self-control in these instances is an issue that is variously defined. Traditional treatments reserve the term self-control for instances in which an individual overrides a dominant response to some immediate stimulus (Baumeister, Vohs, \& Tice, 2007; Fujita et al., 2006; Metcalfe \& Mischel, 1999). From this perspective, self-control is reflected by resisting the desire to reach across the table for more fries, by down-regulating strong emotions in an argument, or by ignoring text messages during a study session.

In contrast, we situate our predictions within a broader view of self-control, which characterizes it as a much wider array of behavioral, cognitive, and affective processes that help one to asymmetrically prioritize long-term over short-term goals (Duckworth, Gendler, \& Gross, 2016; Fishbach \& Converse, 2011; Fujita, 2011; Milkman, Rogers, \& Bazerman, 2008; Schelling, 1984; Thaler, 1991; vanDellen, Hoyle, \& Miller, 2012). This characterization includes a variety of proactive, rather than just reactive, behavioral strategies that support long-term goal pursuit (Ariely \& Wertenbroch, 2002; Gillebaart, Schneider, \& de Ridder, 2015; Milyavskaya \& Inzlicht, 2017; Rogers \& Bazerman, 2008; Trope \& Fishbach, 2000; Zhang \& Fishbach, 2010). From this broader perspective, self-control also involves driving home past the organic grocer rather than the burger joint, installing filters that put a hold on emotional emails, and committing in advance to group study sessions.

Trait self-control, a person's tendency to exercise self-control across time and task domains (Tangney et al., 2004), has traditionally been more closely associated with the reactive, often willful, impulse-control perspective. However, clues are emerging that trait self-control too may represent something broader than effortful resistance. For instance, trait self-control has been linked to the proactive avoidance of temptations (Ent, Baumeister, \& Tice, 2015), to more beneficial habit formation (Adriaanse, Kroese, Gillebaart, \& de Ridder, 2014; Galla \& 
Duckworth, 2015), and to weakened or less frequent desire for tempting stimuli (Hofmann, Baumeister, Förster, \& Vohs, 2012). A recent meta-analysis supported the idea that trait selfcontrol relates to a range of behaviors beyond effortful inhibition (de Ridder, Lensvelt-Mulders, Finkenauer, Stok, \& Baumeister, 2012). If trait self-control reflects variance in a broad set of beneficial self-regulatory tendencies, then it may plausibly be related to identifying autonomous reasons for one's goal pursuit. There are a number of clues in the literature that support this possibility.

\section{Mutual Links to Construal}

Research has demonstrated that people can exert some control over how they view a task in order to make it more interesting (Bandura \& Schunk, 1981; Hackman \& Oldham, 1976; Sansone, Thoman, \& Smith, 2010; Sansone, Wiebe, \& Morgan, 1999). An individual could, for instance, think about otherwise tedious raw material in a way that makes a game out of it (Sansone et al., 1992) or change her focus over the course of a monotonous task to add some feeling of novelty (Suedfeld, 1981). These specific task-construal strategies have not been linked to self-control, but parallel work has demonstrated that self-control processes often protect longterm goals by affecting cognitive representations of the situation at hand. For instance, successful self-regulators are more likely to think about their higher-order goals when they have identified a temptation in the environment (Fishbach, Friedman, \& Kruglanski, 2003) and to activate positive thoughts in association with those goals (Fishbach, Zhang, \& Trope, 2010). More generally, selfcontrol helps people take a more detached, more abstract, and "cooler" view of the situation (Freitas, Gollwitzer, \& Trope, 2004; Freitas, Salovey, \& Liberman, 2001; Fujita, \& Han, 2009; Fujita et al., 2006; Kross, Ayduk, \& Mischel, 2005; MacGregor, Carnevale, Dusthimer, \& Fujita, 2017; Metcalfe \& Mischel, 1999; Mischel \& Ayduk, 2004). While goal-supportive task 
representation has not been as clearly linked to trait self-control, it is notable that the marshmallow test-perhaps the most classic behavioral measure of enduring individual differences in self-control (Mischel, Shoda, \& Rodriguez, 1989)—was, in fact, developed to investigate strategies including cognitive transformations (e.g., Mischel \& Baker, 1975).

Together, this work suggests that self-control can modulate one's view of a given task in ways that support goal pursuit. If we assume that trait self-control at least partially reflects the tendency to enact these processes, it follows that individuals who are high in trait self-control may be more likely to generate or identify autonomous reasons for their actions. Such appraisals could reflect processes that are relatively controlled, effortful, and deliberate (Fujita et al., 2006; Mischel \& Baker, 1975; Sansone et al., 1992), as well as processes that are more spontaneous, effortless, and automatic (Fishbach, Shah, \& Kruglanski, 2004; Fishbach et al., 2010; Fujita \& Han, 2009).

\section{Mutual Links to Ease}

A second form of indirect support for the association between self-control and autonomous motivation comes from their respective associations with the perceived ease of goal pursuit. In one experience-sampling study focused on the experience of temptation, adults who were higher in trait self-control reported lower levels of motivational conflict and fewer instances of having to battle against temptation (Hofmann et al., 2012; see also Galla \& Duckworth, 2015; Imhoff, Schmidt, \& Gerstenberg, 2014). The lack of goal conflict may reflect many contributing factors, but one possibility is that the people who were higher in self-control may have felt less conflicted because they were motivated by autonomous reasons. This possibility is consistent with a separate experience-sampling study, which found that people indeed experienced temptation less frequently and less strongly with respect to their relatively 
more autonomously-motivated goals (Milyavskaya et al., 2015). Prospective research indicates that this very association can lead to successful goal pursuit: Over a semester, students made more progress on their more (versus less) autonomous goals precisely because pursuing those goals felt easier (Werner, Milyavskaya, Foxen-Craft, \& Koestner, 2016). There are many possible linkages within these constellations of variables, but one candidate that emerges is trait self-control. Competing goals present less of a problem for individuals who are higher in selfcontrol and for focal goals that are higher on self-concordance. It is possible that this commonality reflects a direct link between the two.

\section{Trait Self-Control and "Work" versus "Fun"}

Finally, there is some direct, but limited evidence of an association between trait selfcontrol and a task appraisal that might reflect autonomous motivation. This evidence appears among a series of studies designed to test the self-regulatory consequences of completing "work" tasks versus "fun" tasks (Laran \& Janiszewski, 2010). Two of those studies used trait self-control as an operationalization of the work-versus-fun construal of typical depletion tasks (i.e., observing candies without eating them and making a series of decisions; Schmeichel, Vohs, \& Baumeister, 2003; Wang, Novemsky, Dhar, \& Baumeister, 2010). Aiming to validate this operationalization, pilot studies documented a positive correlation between trait self-control and viewing each of the depletion tasks as "an opportunity to have fun" (and a negative correlation between trait self-control and viewing the depletion task as "an obligation to work";

manipulation checks for Experiments 1a and 1b).

While consistent with the hypothesis under investigation, these pilots were not designed to examine the association in depth and are far from conclusive. One shortcoming of these data for testing the current hypothesis (but, importantly, not Laran and Janiszewski's own hypotheses) 
is that the task-construal measures may have confounded locus of causality with valence. While "an opportunity to have fun" and "an obligation to work" align relatively well with autonomous and controlled motivation, respectively, they also seem to represent "a good task" and "a bad task," respectively. Thus, it is unclear if the association with trait self-control reflects the quality of motivation or an evaluative judgment of the task (as in Fishbach et al., 2010). A second shortcoming is that the tasks were intended to be depleting and, as intended, individuals who were lower on trait self-control reported feeling more tired, anxious, and stressed after working on them. It is therefore possible that participants who were lower in self-control reported viewing the tasks more as work and less as fun because the tasks were actually more taxing for them. The current work took a broader view of the association, examined a wider variety of tasks, and employed retrospective, prospective, and real-time paradigms to circumvent this alternative interpretation.

\section{Current Research}

The potential importance of intrapersonal processes for determining the quality of motivation has been acknowledged by self-determination theorists, but remains underdeveloped and has not been examined empirically. In one of the authoritative statements of SDT, Deci and Ryan wrote that, "The natural processes such as intrinsic motivation, integration of extrinsic regulations, and movement toward well-being are theorized to operate optimally only to the extent that [opportunities to meet autonomy and other needs] are immediately present, or, alternatively, to the extent that the individual has sufficient inner resources to find or construct the necessary [opportunities]" (2000, p. 229; italics ours). Whereas most relevant research has focused on whether such opportunities "are immediately present" in the task or situation, the current work addresses the possibility that the individual can "find or construct" such conditions 
(see also Sansone et al., 1992). We examine trait self-control as a potential marker of the "inner resources" that are necessary for such a construction.

Our approach assumes that the trait of self-control represents a density distribution of self-control enactment over time (Fleeson, 2001) and that it is best explained by social-cognitive mechanisms that determine how people pursue goals in different situations (Dweck, 2017; McCabe \& Fleeson, 2016; Fleeson \& Jayawickreme, 2015). Based on this perspective, we ask whether the association between trait self-control and autonomous motivation is more pronounced in situations when self-control is needed most. For example, a primary determinant of the operation of self-control processes is whether they are instrumental at the moment (Trope \& Fishbach, 2000). After completing an activity, engaging self-control to affect the quality of one's motivation toward that activity would no longer be useful. In such a situation, there would be little reason to expect trait self-control to have a strong relation with autonomous motivation.

This instrumentality assumption also explains why the hypothesis implies nothing about a potential relation between trait self-control and controlled motivation. Though many early treatments of self-determination collapsed autonomous and controlled motivation into a single weighted bipolar index, subsequent research acknowledged that they do not necessarily correlate negatively, and often exhibit no correlation at all (see Judge et al., 2005). Moreover, studies that have separated the two often find that they do not necessarily predict relevant phenomena in a strictly opposing manner. For example, one study found that high-school students' autonomous motivation predicted their goal progress, whereas their controlled motivation was unrelated to goal progress (Koestner et al., 2008). Thus, controlled motivation may or may not be antagonistic to goal-pursuit success and well-being, but autonomous motivation is robustly 
supportive of both. We are therefore agnostic about the potential association between trait selfcontrol and controlled motivation.

A secondary aim of this research was to assess whether autonomous motivation might help to explain an established link between trait self-control and well-being (Hofmann, Luhmann, Fisher, Vohs, \& Baumeister, 2014; Wiese et al., 2017). Cross-sectional and experience-sampling studies suggest that people who are higher in self-control tend to be both happier and more satisfied with their life circumstances, in large part because they are better at managing goal conflict. We ask here whether autonomous motivation might be another explanatory mechanism.

We report on four focal studies and two supplementary studies, employing a total of nearly 3,000 participants, that examine the potential association between trait self-control and the experience of autonomous motivation. We first describe an exploratory experience-sampling study (followed by a planned replication) that documented this relation in the wild. We then report on a series of cross-sectional studies that aimed to both generalize and address potential alternative interpretations of the results from the experience sampling methodology (ESM). Finally, we report on an experimental paradigm that allowed us to ask whether the relation between trait self-control and autonomous motivation is an instrumental self-regulatory process or a more invariant overlap of related traits.

We determined target sample sizes for each study in advance of data collection based on considerations of participant availability, study design, and collection method. We report all data exclusions and all manipulations for all studies. We report all measures and manipulations for all studies, though secondary measures for the two ESM studies are relegated to the supplementary online materials (SOM). Datasets and unabridged materials for all studies are available online 
(https://osf.io/ydgur/). We report the number of complete responses in the main text and elaborate on the data collection plan and procedures in the Appendix.

\section{Study 1: Wanting in Everyday Life}

We conducted this experience sampling study as an exploratory first step within a

broader project on goal conflict and purpose. ${ }^{2}$ We asked early-career professionals to report on their goal pursuit eight times per day across five days of the work week. These frequent in situ reports included measures of autonomous and controlled motivation, thus providing an in-depth picture of motivational quality across a variety of circumstances.

In addition to the focal question about trait self-control, the measures we collected allowed us to examine three secondary questions of relevance. First, we were able to examine whether the relation between trait self-control and autonomous motivation varies with subjective fatigue. When people are tired, or believe they are depleted, then pursuing long-term goals feels more difficult, and additional self-regulatory efforts or strategies are required to persist (Baumeister, Bratslavsky, Muraven, \& Tice, 1998; Hofmann, Vohs, \& Baumeister, 2012; Inzlicht \& Schmeichel, 2012; Job, Dweck, \& Walton, 2015; Muraven, Shmueli, \& Burkley, 2006). If the posited relation between trait self-control and autonomous motivation serves a selfregulatory function, then it should be particularly strong when people are feeling fatigued. Indeed, past research suggests that being able to bolster autonomous motivation would be productive in such a setting: People who reported feeling more autonomous motivation during taxing tasks were able to persist longer (Laran \& Janiszewski, 2010; Muraven, Gagne, \& Rosman, 2008). We investigated this potential heterogeneity in the current study using an experience-sampling item that assessed drowsiness. Second, we were able to investigate potential connections between moment-to-moment levels of autonomous motivation and well- 
being at the end of the week. We examined an array of well-being measures, aiming to capture positive and negative components. Third, we examined whether and how individual differences in level of personal agency relate to self-control and autonomous motivation (Vallacher \& Wegner, 1989), an issue that we address in the SOM.

\section{Method}

Research ethics statement. The Institutional Review Board for Social \& Behavioral Sciences at the University of Virginia approved this research study (Protocol \#2013-0004, "Goal Priorities and Decisions - Ecological Momentary Assessment”).

Participants and screening. We sought to recruit early-career professionals, defined as individuals who had been in a full-time job for fewer than 7 years. We adopted this criterion under the presumption that individuals at such a career stage would be working to balance meaningful personal projects with other organizational responsibilities, and that their weeks would consist of a mix of self-directed and other-directed work. Moreover, we presumed that individuals in this population would exhibit many of the psychosocial characteristics that predispose one to burnout risk (Borritz et al., 2005) and we were interested in assessing whether trait self-control might decrease burnout via autonomous motivation.

Our final sample included 196 participants who completed the sampling procedure. Three participants did not complete the follow-up surveys and are therefore excluded from some secondary analyses. Respondents were between 21 and 37 years old $(M d n=27)$ and had been at their current job for approximately 22 months on average, but tenure ranged widely $(S D=16.1$ months). The sample consisted mostly of women $(n=161,82.5 \%$; $n=32$ males, $14.6 \%$; and $n=$ 3 reported gender in a non-binary or declined to say). Most participants received a salary (rather than wages; 81\%). Most reported an annual income between $\$ 65,000$ and $\$ 140,000$ annually 
(93\%), with the rest reporting more than $\$ 140,000$. Participants worked in a variety of positions and domains. Twenty-nine percent of participants had supervisory roles or managed others. Many participants were in the education or library science field (15\%), followed by arts (12\%), business (11\%), social service (9\%), administration (9\%), legal $(8 \%)$, management $(8 \%)$, sciences (7\%), computer/math (7\%), and all other fields (14\%).

Materials. The first phase of data collection included a battery of preliminary surveys, including various time-management and work-style questionnaires. In the current research, we discuss measures of trait self-control and level of personal agency (SOM for full list). The second phase of data collection was the experience-sampling period. The third phase included a battery of post-signaling surveys, including satisfaction with life, sense of purpose, and burnout.

Preliminary surveys. Throughout this work, we measured self-control using the Brief Self-Control Scale (Tangney et al., 2004), a widely used 13-item measure with strong established internal consistency. The Brief Self-Control Scale includes face-valid items such as "I am able to work effectively toward long-term goals," "I am good at resisting temptation," and "People would say that I have iron self-discipline.” The scale is a reliable and valid predictor of many long-term outcomes associated with self-control, and it is one of the most widely used selfcontrol scales because it is domain general and still has good psychometric properties (see de Ridder et al., 2012; Duckworth \& Kern, 2011). In this study, the reliability was high $(\alpha=.84)$, and the distribution was relatively normal $(M=3.37, S D=0.63)$.

The preliminary survey battery also included the Behavioral Identification Form (BIF; Vallacher \& Wegner, 1989). The BIF measures a person's tendency toward high- or low-level identification of actions with higher scores indicating a tendency for high-level identification. For each of a series of behaviors, respondents choose whether it is better described by a given 
low-level or high-level identification. For example, respondents choose whether the action "Making a list" is better described as "Getting organized" or as "Writing things down." The scale demonstrated good internal reliability ( $\alpha=.81, M=13.42$ out of $25, S D=4.90)$.

Participants also completed demographics and reported on characteristics of their job, including company size, their rank within the company, a free response description of their job, and a categorization of their job into one of the 23 "major groups" of occupations from the U.S. government (U.S. Bureau of Labor Statistics, 2010).

Experience sampling survey. Each survey signal opened by asking participants, "What are you up to right now? (If you are between tasks, what were you doing 5 minutes ago?)" and provided a working option (Engaged in a work-related activity) and a non-working option (NOT engaged in a work-related activity). If the participant responded that she was not working, the survey ended. If she indicated that she was working, she was prompted by a free-response question to "Please describe in a word or two what you're working on." Next, participants indicated if they were working with others. They reported whether the activity had been planned in advance or if it was a more spontaneous decision.

The focal autonomous- and controlled-motivation measures for the current investigation appeared next. We asked participants to "help us understand your reason(s) for working on this activity at this time." The prompt said, "I am working on this right now..." and then listed 7 potential reasons, which participants marked on a 4 -point scale from $1=$ not at all true to $4=$ completely true. The focal items were adapted from established items used in research on selfconcordance, with slight wording changes to accommodate the broader protocol and measurement context (Sheldon \& Elliot, 1998; also, e.g., Judge et al., 2005; Koestner et al., 2008; Sheldon \& Kasser, 1995). We assessed intrinsic motivation using the item, “...because it 
is fun and enjoyable to be working on"; identified motivation using, “...because it is for a project I truly care about”; introjected motivation using, “... because I would feel ashamed, guilty, or anxious if I didn't”; and external motivation using two items, “...because it has an official deadline approaching” and “...because someone else is waiting on me or depending on me.” Self-determination theorists typically use a single, more general, item to measure external motivation, “... because somebody else wants you to, or because you'll get something from somebody if you do it." We adjusted this item more than others, largely to fit better in the work context, and also to potentially address other questions (not directly relevant to the current hypotheses) about urgency (deadlines) and social pressures (someone waiting). We also added two additional reasons to this list for use in other investigations (cognitive closure, “...because I just don't want to think about it anymore"; and goal-gradient, “...because it is hard to stop when I am so close to finishing it").

Consistent with SDT conceptualizations, intrinsic motivation and identified motivation were highly related in our sample and we therefore combined them into an index of autonomous motivation ( $\alpha=.87$; this and all subsequent $\alpha$ 's were calculated at the person-level). Additionally, the single introjected and two external motivation items were highly related $(\alpha=$ $.68)$ and we therefore combined them into an index of controlled motivation. Participants could also write their own reason for acting if it was not covered by any of the provided options. Most participants never provided their own reason $(60 \% ; n=118)$; of those who did at least once, overall use of the free-response option was infrequent ( $M d n=10 \%$ of working responses).

Participants then responded to single items assessing level of motivation, goal conflict, and satisfaction with time use (SOM). Finally, participants indicated their current affect, using single items representing the top-loading terms for each of the four factors of the Job Affect 
Scale (Burke, Brief, George, Robserson, \& Webster, 1989). Specifically, participants indicated how they felt right now from $1=$ not at all or slightly to $5=$ extremely on the items "drowsy," "relaxed," "enthusiastic," and "nervous." We used drowsiness as a proxy for subjective fatigue. Post-signaling surveys. After the signaling period, participants reported on their wellbeing and life satisfaction. We included the 5-item Satisfaction with Life Scale to assess overall well-being (SWLS; Diener, Emmons, Larsen, \& Griffin, 1985). The SWLS includes face valid items such as "In most ways my life is close to my ideal" $(1=$ strongly disagree to $7=$ strongly agree) and is widely used in well-being research to assess one's conscious, relatively more cognitive (than affective) evaluation of his or her quality of life (Pavot \& Diener, 2008; current sample: $\alpha=.86 ; M=4.75, S D=1.22)$.

We also included a 10-item Purpose scale that has been used in psychiatric research (Boyle, Buchman, Barnes, \& Bennett, 2010; adapted from Ryff, 1989). This scale measures the extent to which people feel a sense of agency, directedness, and meaning in their lives. In the current version, respondents indicated their agreement or disagreement with statements such as, "I have a sense of direction and purpose in life" ( $1=$ strongly agree to $5=$ strongly disagree $)$. To make the scoring intuitive, we reverse-scored items such as the example item so that higher scores indicated more purpose in life (current sample: $\alpha=.86 ; M=3.70, S D=0.66$ ).

We included 13 items of the Cophenhagen Burnout Inventory (CBI). We administered the Self and Work sub-scales, but excluded the Client sub-scale because client interactions were unlikely to be a part of all respondents' jobs (Kristensen, Borritz, Villadsen, \& Christensen, 2005). The CBI assesses how physically and emotionally exhausted the respondent feels within the work context and life more generally. Items included, "How often do you feel tired?" measured on a 5-point scale with fixed values $0-100(0=$ Never $/$ Almost never, $25=$ Seldom, 
$50=$ Sometimes, $75=$ Often, $100=$ Always) and, "Is your work emotionally exhausting?" measured on a 5-point scale with fixed values $0-100(0=$ To a very low degree, $25=$ To a low degree, $50=$ Somewhat, $75=$ To a high degree, $100=$ To a very high degree . Items were highly correlated $(\alpha=.91)$ and we combined them into one measure of burnout $(M=44.09, S D=$ 16.90). Additional scales that do not help address the current hypotheses are listed in the SOM.

Procedure. We recruited and ran participants across 5 weeks of active data collection during the summer of 2015. Upon eligibility confirmation, participants provided informed consent and indicated a continuous eight-hour window during which they would be working and able to receive experience-sampling surveys via text message.

Experience sampling procedure. The 5-day experience-sampling portion of the study began on the first working day of the work week following participant registration (usually Monday, but Tuesday during holiday weeks). We used SurveySignal (Hofmann \& Patel, 2015; surveysignal.com) to manage the signal randomization and send text messages to participants' registered smartphones. On each experience-sampling day, the software randomly distributed 8 signals across an eight-hour window with the restriction that signals be separated by at least 20 minutes. The signal arrived as a text message. The text message included a link that would open a survey in an online browser (administered using Qualtrics Survey Software). The survey was formatted to work well on smartphones. On average, people responded to $84 \%$ of signals received $(M d n=88 \%$, range: $25 \%-100 \%)$. They reported current engagement in a work activity on $66 \%$ of those responses ( $M d n=68 \%$, range: $22 \%-100 \%)$. The SOM includes supplementary analyses that try to assess the role of response bias in the obtained results. We did not identify any patterns that suggested a strong internal-validity threat. 
Responses initiated within 10 minutes of the signal activated the entire survey. Responses initiated between 10 minutes and one hour after the signal prompted an abbreviated survey. In these instances, participants saw a prompt that said, "Uh oh! You were not able to respond within 10 minutes so we closed the survey for that time period. The signal came at [time], $[\mathrm{x}]$ minutes ago. It would be helpful to know what you were doing at that time." Possible responses were "I was not engaged in a work activity anyway," "I was working but did not have my phone available," "I was working but did not notice or could not respond to the text message," "I was in a meeting and could not respond," and "Other, [free response]." If the participant indicated that she or he was working or in a meeting, the survey continued to the free-response description of "what you were working on," the two items about the circumstances of the work, and then autonomous, controlled, and other reasons items (adapted to be in the past tense, but otherwise unchanged). The abbreviated survey ended at this point. Responses initiated more than one hour after the text message prompted a "closed survey" message and were recorded as a missed signal. Responses to the abbreviated survey were included in all appropriate analyses. To increase the number of responses we received from each participant, we initiated a "make-up day" of signaling if needed (SOM).

Post-signaling procedure. The day after the experience sampling phase ended, we emailed participants a link to the post-signaling surveys. We sent reminder emails one and two weeks after the initial post-signaling survey request. Upon completion of this final set of surveys, participants received debriefing information. Participants received $\$ 36$ for their participation and those who responded to at least $80 \%$ of their signals were awarded a $\$ 5$ Amazon.com gift card and entered into a lottery for one of three $\$ 50$ Amazon.com gift cards. 


\section{Results}

Analysis Strategy. We used R Version 3.4.0 (R Core Team, 2017) and analyzed multilevel models using the "Ime4" package (Version 1.1-13; Bates, Maechler, Bolker, \& Walker, 2015). All signaling data are nested within person and so multilevel models include a random intercept. Moment-level predictors are centered within person. Person-level predictors are grand-mean centered. We focused on unstandardized regression coefficients $(b$, with $95 \%$ confidence intervals), but present standardized coefficients $(\beta)$ for the interested reader. We include random slopes when supported by the data (Barr, Levy, Scheepers, \& Tily, 2013). We also examine a number of mediation models, though we note at the outset that this analytic approach is still fundamentally correlational in nature and cannot distinguish between alternative causal models (Fiedler, Schott, \& Meiser, 2011).

Descriptives. At the person-level, average autonomous motivation across the week $(M=$ 2.12, $S D=0.60)$ was lower than average controlled motivation $(M=2.64, S D=0.49), t(195)=-$ 9.78, $p<.001$. Autonomous motivation was uncorrelated with controlled motivation, $r(194)=$ $.07, p=.32,95 \%$ CI $[-.07, .21] .^{3}$ Person-level descriptives and correlations are in Table 1.

Trait self-control and autonomous motivation. In a multi-level model with a random intercept of person $(\mathrm{ICC}=.37$ ), we regressed autonomous motivation on trait self-control. Trait self-control was a significant predictor of autonomous motivation, $b=0.21,95 \%$ CI [0.08, 0.34], $\beta=0.14, t=3.18, p=.002$ (see Figure 1). There was also a significant negative relation between trait self-control and controlled motivation, $b=-0.12,95 \%$ CI $[-0.23,-.02], \beta=-0.09, t=-2.26$, $p=.025$. In follow-up analyses, we found that level of personal agency, as measured by the BIF, correlated with trait self-control, but did not account for the association between trait self-control and autonomous motivation (see SOM). 
The role of fatigue. To examine whether self-control was differentially associated with autonomous motivation depending on one's level of subjective fatigue, we investigated the potential cross-level interaction between trait self-control (at the person level) and drowsiness (at the moment level). We regressed autonomous motivation on trait self-control, participantreported drowsiness, and their interaction, using a multi-level model with a random slope of drowsiness $(\mathrm{ICC}=.01)$. Self-control was positively associated with autonomous motivation, $b=$ $0.21,95 \%$ CI [0.08, 0.34], $\beta=0.15, t=3.21, p=.002$; drowsiness was negatively associated with autonomous motivation, $b=-0.11,95 \%$ CI $[-0.15,-0.09], \beta=-0.10, t=-7.53, p<.001$; and, importantly, the main effects were qualified by a significant interaction, $b=0.07,95 \%$ CI $[0.02$, 0.12 ], $\beta=0.05, t=2.82, p=.005$; see Figure 2. When people were feeling more fatigued during the week, they were less likely to feel autonomously motivated. However, among individuals with higher levels of self-control, drowsiness was less associated with autonomous motivation. In other words, the relation between self-control and autonomous motivation was relatively more pronounced when people were fatigued. One potential interpretation is that self-control provided a buffering effect against drowsiness.

Of course, given the correlational nature of the data, other interpretations are also possible. There is also support for an alternative model that treats drowsiness as the outcome variable. When we regressed drowsiness on trait self-control, autonomous motivation, and their interaction, using a multi-level model with a random slope of autonomous motivation $(\mathrm{ICC}=$ .02 ), we found that self-control was negatively associated with drowsiness, $b=-0.28,95 \% \mathrm{CI}$ [$0.41,-0.15], \beta=-0.17, t=-4.14, p<.001$; autonomous motivation was negatively associated with drowsiness, $b=-0.19,95 \%$ CI $[-0.24,-0.15], \beta=-0.13, t=-8.00, p<.001$; and, importantly, the main effects were qualified by a significant interaction, $b=0.14,95 \%$ CI $[0.06$, 
$0.21], \beta=0.06, t=3.69, p<.001$. Thus, another possible interpretation is that people who are lower in self-control find a lack of autonomous motivation to be depleting, whereas people who are higher in self-control are somewhat protected against this effect. ${ }^{4}$

Well-being. Finally, to determine whether the data are consistent with a model in which self-determination helps to explain the relation between trait self-control and well-being, we conducted a series of person-level mediation models treating trait self-control as the predictor, average autonomous motivation over the week as a mediator, and three different well-being measures as outcomes. Indeed, there were significant total effects of trait self-control on measures of life satisfaction, purpose, and (lower) burnout; and autonomous motivation explained some of the variance in each case (Table 2). This analysis cannot rule out other causal models, but the data are at least consistent with a model in which autonomous motivation partially mediates the relation between trait self-control and well-being.

\section{Discussion}

This study documented a positive association between trait self-control and autonomous motivation. The real-world nature of the paradigm positions it as more than an existence proof that trait self-control can be related to autonomous motivation. Among a relatively diverse sample of people, pursuing a relatively diverse set of projects and goals, we found that trait selfcontrol does relate to autonomous motivation. As young professionals were navigating their many, sometimes conflicting, sometimes tedious work tasks throughout a week, those who were higher in self-control were more likely to find interest and/or meaning in what they were doing.

Further, hinting at a self-regulatory account, we found evidence consistent with the possibility that the association depends on subjective fatigue. When people were more fatigued, they were less likely to identify autonomous reasons for their work, with trait self-control 
potentially acting as a buffer against the fatigue effect. Among those higher in self-control, fatigue did not relate to autonomous motivation as strongly. It is also noteworthy that trait selfcontrol remained a significant predictor of autonomous motivation when controlling for subjective fatigue. This finding moves the current account beyond the closest extant evidence by ruling out an alternative interpretation whereby lower self-control individuals might indicate less autonomous motivation simply because they are more depleted (cf., Laran \& Janiszewski, 2010).

Moreover, we found that average moment-to-moment autonomous motivation accounted for some of the documented relation between self-control and well-being (Hofmann et al., 2014; Wiese et al., 2017), and extended the scope of that relation to include burnout and purpose. Previous research has linked autonomy to lower burnout (Van den Broeck, Vansteenkiste, De Witte, \& Lens, 2008) and the current work suggests that trait self-control may be relevant one step earlier in the process, as a contributor to autonomous motivation (though, again, other causal sequences are possible). Understanding both proximal and distal antecedents of burnout is important given the negative association between burnout and both job performance and health outcomes (Maslach, Schaufeli, \& Leiter, 2001). Documenting these paths helps to paint a richer picture of the relation between self-control and many facets of well-being, including happiness; purpose or meaningfulness; and a lack of exhaustion, cynicism, and detachment.

These findings are all consistent with the hypothesized relation between trait self-control and autonomous motivation, but many open questions remain based on this initial study. First and foremost, this ESM study was an exploratory effort designed to address a number of broad questions about motivation and goal conflict in daily life. While the measures that are omitted from this article did not afford additional tests of the hypothesis, we did address many exploratory questions with these data. It was therefore critical to conduct a close replication in 
which we planned to assess the basic association between trait self-control and autonomous motivation We pursued this research aim in Study 1R. Second, we cannot definitively rule out the role of biased responding. We did not find evidence to support the most compelling patterns of biased responding that we could think of (see SOM), but others are possible. Studies 2 and 3 employ a cross-sectional design to ensure that selective responding is not responsible for the observed relation. Third, in the experience-sampling context, we cannot dismiss the possibility that higher- and lower-self-controlled individuals may be choosing different tasks, rather than representing or experiencing the same tasks differently. Studies 3 and 4 use a fixed task.

\section{Summary of Study 1R: An Experience Sampling Replication}

We designed Study 1 as a broad, exploratory study. Our first priority in investigating the observed relation between trait self-control and autonomous motivation was therefore to determine if it replicated in a more confirmatory fashion. We identified an opportunity to do so by embedding the study in a larger experience-sampling study that the third author of this paper was involved in. That study was designed to investigate strategies involved in self-regulation during unpleasant activities and the data are described in much more detail elsewhere (Hennecke, Czikmantori, \& Brandstätter, 2018). For brevity, we describe an overview of the study here, with full procedural details in the SOM. The research team conducting that study was already planning to measure trait self-control and to administer an experience-sampling protocol that asked participants about their current activities and motivation. With length limitations in mind, we could not add the full set of items from Study 1, but we were able to assess the two extremes of the self-determination spectrum using an intrinsic-motivation item already included in the protocol and an external-motivation item that we added. 
This study was deemed exempt by the ethics committee of the Faculty of Philosophy at the University of Zurich, Switzerland. Participants for this study $(N=268 ; 229$ female, $18-54$ years old, $M d n=22$ ) were recruited through a large participant pool at the University of Zurich. All items were presented in German and are translated here for reporting. In a preliminary survey battery, participants completed a German translation of the Brief Self-Control Scale (Bertrams \& Dickhäuser, 2009; translated from Tangney et al., 2004; $\alpha=.88, M=4.16, S D=0.95$ ). Signaling occurred during a 14-hour window across 7 consecutive days, with signals randomly assigned in 2-hour blocks separated by at least one hour. At every signal, participants first responded to two items about their current affective state. Next, a block of questions referred to whether participants had, within the hour, engaged in an unpleasant activity; its content (e.g., “study-related activity", "work”) and hedonic qualities; any persistence strategies participants may have used; and their success in remaining persistent.

Next, a second block of questions referred to participants' most recent activity (which may have been the aforementioned unpleasant activity), and its content and hedonic qualities. Within this block, participants completed the measures that we examined for this study. Specifically, participants indicated, with respect to their most recent activity, "How much fun was the last activity before the questionnaire?" ( $1=$ no fun at all to $7=$ a lot of fun; $M=4.73, S D$ $=0.68$ ). After a couple of intervening questions, participants then indicated their experience of external motivation, "To what extent did you do this activity because of a looming deadline or because another person was waiting for you to do it?" (the scale changed from a 7-point to a 5point scale to fit in with overall survey flow; $1=$ not at all to $5=$ very strongly; person-level $M=$ $1.94, S D=0.57$ ). For continuity, we will use the broader terms autonomous and controlled motivation to refer to the constructs represented by the single intrinsic and external items, 
respectively. Autonomous and controlled motivation were negatively correlated, $r(266)=-0.21$, $p=.001,95 \%$ CI $[-0.34,-0.07]$.

To determine if there was an association between trait self-control and autonomous motivation, we ran a multi-level model regressing autonomous motivation on trait self-control with a random intercept of person $(\mathrm{ICC}=.11)$. As predicted, and replicating the exploratory result in Study 1, trait self-control was a statistically significant predictor of autonomous motivation, $b=0.12,95 \% \mathrm{CI}[0.04,0.20], \beta=0.07, t=2.84, p=.005 .^{5}$ There was not a significant relation between trait self-control and controlled motivation, $b=0.03,95 \% \mathrm{CI}[-0.04$, 0.10], $\beta=0.02, t=0.81, p=.42$ (see Figure 1$)$.

In both Study 1, which was more exploratory in nature, and Study 1R, which was more confirmatory in nature, we observed a small, but reliable positive association between trait selfcontrol and autonomous motivation in the real world. This association appeared within a sample of early-career professionals going about their daily workdays for a week, and within a sample of university community members (mostly students, but also staff and other locals) going about their personal and professional activities across a full week and weekend. Suggesting that the effect of trait self-control is relatively targeted, there was not a similar positive relation with controlled motivation in either study. With increased confidence in the reliability of the observed association, we moved on in Studies 2 and 3 to cross-sectional designs that would allow us to better characterize the nature of the observed relation.

\section{Study 2: A Cross-Sectional Approach}

The central aim of Study 2 was to test whether the relation between trait self-control and autonomous motivation held when we used a design in which biased responding did not pose a potential validity threat. We took biased responding out of the equation by employing a simple 
cross-sectional design. We used Amazon Mechanical Turk (MTurk) to recruit individuals during their workday and measured trait self-control and autonomous motivation at a single time-point. We used a "hidden screening" procedure to select participants who were completing MTurk tasks during a brief break from their workday. We asked them to report on their motivation for their most recent work task. Thus, we were able to again examine people's motivation in a natural setting, but without some of the potential pitfalls of an ESM approach.

\section{Method}

Research ethics statement. The Institutional Review Board for Social \& Behavioral Sciences at the University of Virginia approved all subsequent studies in this manuscript (i.e., Studies 2—4; Protocol \#2013-0005, "Goal Priorities and Decisions”).

Participants. We recruited MTurk participants for participation in a 4-minute $(\$ 0.50)$ study on "your day and priorities." To field more participants who were in the middle of their workday, we opened the study from $11 \mathrm{am}$ to $3 \mathrm{pm}$ local time. To simplify the process of determining local time, we set IP restrictions and opened one wave to participants in the Eastern time-zone and one wave to participants in the Pacific time-zone at the appropriate times (Appendix for details). In the end, 748 participants completed the study (356 female, 387 male, and 5 who reported non-binary responses or declined to report; 18-74 years old, $M d n=33$ ).

Procedure. We used a "hidden screening" procedure rather than advertising the qualification standards because we did not want participants to have any incentive to lie about their employment status (i.e., to report being at work so they would be eligible for an additional study; Chandler \& Paolacci, 2017). Instead, we used a multi-item screening procedure that was embedded within a number of mundane questions about what the respondent had accomplished that morning. Participants reported the time they woke up, whether they had exercised, and what 
time they went to work that morning. Participants who reported having the day off or being unemployed were funneled off into Study 3, running concurrently. Participants who reported a work start-time were then asked if they were done for the day or if they were taking a break and planned to return to work. Participants who reported being done for the day were also funneled into Study 3. Thus, participants were funneled into the current study if they reported being employed, were at work, and were currently taking a break.

After responding to the screening questions, participants moved to the sections that constitute the focal study. Participants were randomly assigned to complete the Brief SelfControl Scale $(\alpha=.88 ; M=3.60, S D=0.70)$ at the beginning of the study or at the end of the study, just before demographics. Participants then identified their most recent work task. Following a similar progression as in Study 1's ESM protocol, they indicated whether the task was scheduled and whether they were working on their own or with others. They also reported how long ago they had started working on the task, when they stopped working on the task, and whether they had completed the task.

Then, participants read the prompt for the measure of autonomous and controlled motivation. Measures were similar to Study 1, with slight changes. First, we changed the prompt to fit better with the retrospective nature of the cross-sectional design. The prompt said, "Help us understand your reason(s) for working on this task when you did. In other words, why did you choose to work on this task over others? I chose to work on this task because...." Participants indicated to what extent each of four reasons was the impetus for their decision using a scale from $1=$ not at all to $4=$ completely. We measured autonomous motivation using the same two items from Study 1 (but in the past tense). We measured controlled motivation using the two external items (social and deadline) from Study 1. (In hindsight, it would have been preferable 
for the sake of consistency to include introjected motivation as well, but at the time we were focused on external motivation as the main counterpoint to autonomous motivation.) By random assignment, participants saw the reasons listed in one of two orders. If there was an additional reason for their decision, participants could write in their own response, but they did not rate it. Intrinsic motivation $(M=2.11, S D=1.03)$ and identified motivation $(M=2.54, S D=1.10)$ were correlated, $r(746)=.51, p<.001$, and were averaged into an index of autonomous motivation $(M$ $=2.32, S D=.92)$. Deadline-based external motivation $(M=2.57, S D=1.21)$ and social-based external motivation $(M=2.86, S D=1.16)$ also correlated, $r(746)=.32, p<.001$, and were averaged into an index of controlled motivation $(M=2.72, S D=0.96)$. Autonomous motivation was not correlated with controlled motivation, $r(746)=-.03, p=.44,95 \%$ CI $[-.10, .04]$.

Next, participants reported on their subjective experience while working. Participants reported their level of motivation and feelings of goal conflict. ${ }^{6}$ Participants also reported how satisfied they were with how they were spending their time on a scale from $1=$ very dissatisfied to $7=$ very satisfied (SOM for satisfaction results). Finally, participants reported their age, gender, and educational attainment before they were thanked for their time, debriefed, and paid.

\section{Results}

Descriptives. Most participants reported working alone (616 alone, 104 in a small group of 2-4 people, and 28 in a large group). Three hundred seventy-eight participants reported that the last work task occurred during unstructured work time; 213 participants said they had scheduled the task in advance; 105 participants said someone else had scheduled the task in advance; and 52 participants said the last work task occurred as part of a standing meeting.

Trait self-control and autonomous motivation. Consistent with predictions, trait selfcontrol correlated positively with autonomous motivation, $r(746)=.19, p<.001,95 \%$ CI $[.12$, 
.25]. Trait self-control did not correlate with controlled motivation, $r(746)=.06, p=.12,95 \% \mathrm{CI}$ $[-.02, .13]$ (see Figure 1). We tested for order effects by regressing autonomous motivation on order, trait self-control, and their interaction. There was no main effect of order, $p=.849$, nor an interaction with trait self-control, $p=.190$, only the main effect of self-control, $b=0.31,95 \% \mathrm{CI}$ $[0.18,0.45], \beta=0.24, t(744)=4.49, p<.001$. Follow-up analyses revealed correlational evidence consistent with a mediational model whereby autonomous motivation partially explained the effect of self-control on momentary satisfaction with time use (SOM).

\section{Discussion}

Once again, consistent with the hypothesis, we observed a positive association between trait self-control and autonomous motivation. By employing a cross-sectional design and asking participants about their most recent work activity, we could be more confident that decisions about whether to respond to the survey were not responsible for the observed association. For response decisions to explain the results of Study 1 and Study 2, it would have to be the case that individuals higher (vs. lower) in self-control are more likely to pause in the middle of an autonomously motivated activity to fill out a survey when signaled (Study 1) and that they are more likely to spontaneously take an MTurk break immediately after making some progress on an autonomously motivated activity (Study 2). This very specific explanation seems implausible. If anything, we would expect individuals higher (vs. lower) on self-control to be more committed to their autonomously-motivated tasks and to persevere on them for longer.

It is also informative that the positive association holds regardless of the order of measurement. The positive correlation when the self-control measure came second shows that it was not necessary to engage self-control processes by priming them through the act of administering the scale. And, vice versa, the positive correlation when the Self-Control Scale 
came first shows that reflecting on an autonomously motivated activity did not "cause" the relation by inflating self reports of trait self-control.

We used an idiographic approach to assess motivation in Studies 1 and 2. Individuals rated their own tasks as they were going about their own business (Study 1) or as they were taking a short break from their own business (Study 2). Given this approach, we cannot rule out the possibility that higher- and lower-self-control individuals are simply working on different tasks. In Study 3, we mixed an idiographic and a nomothetic approach. We again asked participants about their motivations for an upcoming activity of their own choosing, but we also asked them about their motivations for doing studies on MTurk. If the relation still appears in the latter case, it would suggest that trait self-control is associated with representing or experiencing the same activity as more autonomously motivated.

\section{Study 3: Seeing More Autonomous Motivation in the Same Task}

Study 3 followed the same procedure as Study 2, except with some changes to the items used to measure autonomous motivation. The participants in this study were those who were determined by the hidden-screening procedure in Study 2 to not be at work. Thus, the sample is a collection of individuals who were not currently in the middle of their workday (either because they were not currently employed or because they were not at work at the moment). The key changes from Study 2 were that we asked about motivation for an upcoming personal task and about motivation for doing MTurk studies. If higher self-control individuals report more autonomous motivation even when the task is in the future, this again suggests that differences as a function of trait self-control cannot be attributed to different levels of depletion from the task itself (cf., Laran \& Janiszewski, 2010). It would also suggest that trait self-control is not just helping people to rationalize their investment in current or recently-completed activities. 
Additionally, if higher self-control individuals report more autonomous motivation for working on MTurk - a fixed task across participants - this is stronger evidence that the motivational differences are based at least in part on different representations or experiences of the task rather than on different choices of what to pursue.

\section{Method}

All participants who were not currently working as defined by the multi-item screening measure employed in Study 2 were directed to this study. In the end, 508 participants completed the study (254 female, 247 male, and 7 who reported non-binary responses or declined to report; 18-77 years old, $M d n=31$ ). As in Study 2, participants were randomly assigned to complete the Brief Self-Control Scale $(\alpha=.88, M=3.52, S D=0.71)$ before reporting their task motivation or after. To set up the motivation assessment, we asked participants to briefly describe "the most important thing" they were hoping to accomplish that day. Participants reported whether the task was scheduled in advance and whether they would complete it with others or alone.

Next, in counterbalanced order, participants reported on their reasons for putting the upcoming task on their to-do list and their reasons for working on an MTurk study. For the upcoming task, we asked: "You said that today you want to accomplish the following task: ' $\{$ task $\}$ ' Help us understand your reason(s) for including this task on your to-do list today. I have included this task ..." and participants indicated their agreement with the same four items from Study 2 (intrinsic, identified, deadline-based external, and social-based external) using a 4-point scale from $1=$ not at all true to $4=$ completely true. Intrinsic motivation for the participant's future task $(M=2.20, S D=1.14)$ and identified motivation for the participant's future task $(M=$ 2.90, $S D=1.08)$ were correlated, $r(506)=.32, p<.001$, and we averaged them into an autonomous motivation index $(M=2.55, S D=.90)$. Deadline-based external motivation for the 
participant's future task $(M=1.86, S D=1.11)$ and social-based external motivation for the participant's future task $(M=2.10, S D=1.15)$ were also correlated, $r(506)=.34, p<.001$, and we averaged them into a controlled motivation index $(M=1.98, S D=.92)$. Autonomous motivation was not correlated with controlled motivation, $r(506)=.03, p=.56,95 \%$ CI [-.06, $.11]$.

For the MTurk survey ratings, we asked, "The following questions refer to your participation in this MTurk research study. Help us understand your reason(s) for taking part in this study right now. I am completing this MTurk study ..." and participants indicated their agreement with the same four items. Intrinsic motivation for MTurk $(M=2.62, S D=.99)$ and identified motivation for MTurk $(M=2.08, S D=1.02)$ were correlated, $r(506)=.51, p<.001$, and we averaged them into an autonomous motivation index $(M=2.35, S D=.87)$. Deadlinebased external motivation for MTurk $(M=1.54, S D=.92)$ and social-based external motivation for MTurk $(M=1.50, S D=.89)$ were also correlated, $r(506)=.47, p<.001$, and we averaged them into a controlled motivation index $(M=1.52, S D=.77)$. Autonomous motivation was correlated with controlled motivation, $r(506)=.31, p<.001,95 \%$ CI $[.23, .39]$.

Consistent with Study 2, participants then reported their experience of conflict and satisfaction while completing the MTurk survey. Finally, participants reported their age, gender, and education attainment.

\section{Results}

Trait self-control and autonomous motivation for a fixed task. As predicted, trait selfcontrol was positively correlated with identifying autonomous reasons for completing the current MTurk survey, $r(506)=.26, p<.001,95 \%$ CI $[.18, .34]$. It did not correlate with identifying controlled reasons, $r(506)=-.03, p=.531,95 \% \mathrm{CI}[-.11, .06]$ (see Figure 1). We tested for order 
effects by regressing autonomous motivation for the MTurk survey on order, trait self-control, and their interaction. There was no main effect of order, $p=.950$, nor an interaction with trait self-control, $p=.509$, only the main effect of trait self-control, $b=0.36,95 \% \mathrm{CI}[0.22,0.49], \beta=$ $0.29, t(504)=5.10, p<.001$.

\section{Trait self-control and autonomous motivation for an upcoming personal task. The} positive relation between self-control and autonomous motivation also held for the participant's own task ratings. Self-control was positively correlated with autonomous motivation, $r(506)=$ $.15, p<.001,95 \%$ CI $[.06, .23]$. This replicates our findings from Studies 1 and 2 and extends the evidence to include future tasks. We also found that self-control was negatively correlated with controlled motivation in this instance, $r(506)=-.09, p=.04,95 \% \mathrm{CI}[-.18,-.00]$. There was no evidence for order effects on the participant's rating of autonomous motivation for their own task, $p=.264$, or an interaction with trait self-control, $p=.289$, while the main effect of trait selfcontrol remained significant, $b=.25,95 \%$ CI $[0.10,0.39], \beta=0.19, t(504)=3.31, p=.001$.

\section{Discussion}

In Study 3, we took advantage of the cross-sectional study design to ask participants to indicate their autonomous motivation for the same task, the MTurk survey itself. In this study, the higher autonomous motivation reported by higher self-control participants cannot be a consequence of those individuals working on different tasks than their lower self-control counterparts. We also extended the finding by demonstrating that the positive relation between self-control and autonomous motivation holds when participants are looking forward to upcoming tasks, indicating that the effect is more than post-hoc rationalization (Bem, 1972;

Cialdini, Trost, \& Newsom, 1995; Cooper \& Fazio, 1984; Festinger, 1957). It also rules out the 
possibility that all of the effects are attributable to lower self-control individuals feeling more negatively about tasks that just depleted them.

Across Studies 1, 1R, 2, and 3, we observed an association between trait self-control and autonomous motivation for professional goals, personal goals, and a fixed goal. The fundamental aim of Study 4 was to better assess the nature of that relation. Study 1 provided suggestive evidence of a self-regulatory relation, showing that trait self-control was particularly important for autonomous motivation when fatigue was high; but falls short of providing causal evidence of such dependence. We addressed this open question in Study 4 by manipulating the potential instrumentality of boosting autonomous motivation.

\section{Study 4: Manipulating Instrumentality}

We have proposed that trait self-control might be related to autonomous motivation in a self-regulatory fashion. However, a viable alternative is that the association is incidental, like a trait-based spandrel that does not reflect a direct relation between the two and merely arises from shared variance with a third variable. For example, it could be the case that individuals who are higher in self-control are also high-level agents (those who consistently construe actions in more abstract terms; Vallacher \& Wegner, 1989), and that high-level agents consistently identify more autonomous reasons for their actions because they see the broader meaning of what they are doing. Study 1 provides evidence against this particular third-variable mechanism, but other variations are nonetheless possible.

If it turned out that trait self-control was related to autonomous motivation in a flexible fashion, based on self-regulatory challenges in the environment, this would provide strong evidence for the self-regulatory interpretation. During goal pursuit, people pay more attention to and feel more positively about the means that help them achieve their goal. This goal-based 
evaluation is a hallmark of self-regulation (Aarts, Dijksterhuis, \& De Vries, 2001; Ferguson \& Bargh, 2004; Fishbach et al., 2010; Förster, Liberman, \& Friedman, 2007; Markman \& Brendl, 2000; Moors, De Houwer, \& Eelen, 2004). Thus, if the association between trait self-control and autonomous motivation reflects even a distal causal relation, whereby being high in self-control indicates a higher likelihood of engaging self-control processes that target autonomous motivation (whether deliberately or automatically), then the association should be stronger when a given task is ongoing than when it is complete (Trope \& Fishbach, 2000).

This does not imply that flexibility is a necessary condition for all self-regulatory interpretations. A more stable association between trait self-control and autonomous motivation could still be self-regulatory in nature. For example, it could be the case that individuals high in self-control so regularly create or focus on the autonomous reasons for their action that it becomes a regular, habitual, or crystalized tendency. In this case, the association would not necessarily depend on self-regulatory challenges in the moment. This sets up the following logic: If the relation between trait self-control and autonomous motivation is flexible based on instrumentality, this would be strong evidence of a self-regulatory interpretation; if the relation is not flexible, other approaches would be needed to help determine the nature of the association.

The instrumentality prediction may seem at odds with our earlier studies that asked about recently-completed tasks, but this neglects an important distinction between regularly completed real-world tasks and novel experimental paradigms. Our assumption is that people will encounter most of their completed real-world tasks again in the future. If someone just finished filing reports in real life, it would be useful to boost the autonomous motivation associated with "filing reports" because the person will probably have to do it again tomorrow or next week. This experiment, in contrast, employs a novel experimental task that people are exceedingly unlikely 
to encounter again in the future. If someone just finished completing a strange experimental task, it would not be useful to boost the autonomous motivation associated with that specific task because the person will probably never do it again. Research in the areas of learning and motivation converge on the idea that people "are sensitive to the prospective utility of responses-responses that can fulfill future goals seem to make more indelible impressions on participants' memory than do responses that will not be useful later" (Ferguson \& Barsh, 2004, p. 559; Markman \& Brendl, 2000; Marsh, Hicks, \& Bryan, 1999; Roediger, 1996).

\section{Study 4 Precursor}

In our first effort to test the instrumentality hypothesis (details in SOM), we attempted to manipulate instrumentality by asking participants to consider reasons for working on a task that they themselves would have to complete or that they thought only other people would have to complete. The assumption here was that it would be instrumental for participants to boost their sense of autonomous motivation if they thought they would soon complete the task, but not if they only believed that others would need to do so. We created a tedious vigilance task (the "Security Detection Task") in which participants would monitor inherently boring stimuli for many trials, looking for rare 'hits.' The task was not inherently interesting or obviously valuable.

We attempted, perhaps unsuccessfully, to strike a delicate balance with this procedure. On one hand, we needed to ensure that participants' understanding of the task was the same across conditions. On the other hand, we recognized at the outset that to achieve sufficient statistical power, we would need to recruit a large sample and would need to use an online pool to do so. The countervailing tension, then, was to ensure that participants knew how tedious the task was, but did not drop out disproportionately in the first- versus third-person condition. Our attempt to achieve this balance involved explaining the task, administering five practice trials, 
and then asking participants to report on their reasons (real condition) or presumed reasons (hypothetical condition) for working on the task. In the real condition, participants went through these preliminary steps expecting to complete the full Security Detection Task. In the hypothetical condition, participants went through these preliminary steps knowing that the Security Detection Task was a "task that we are going to use in OTHER MTurk studies."

Across conditions, we once again replicated the simple association between trait selfcontrol and autonomous motivation, $r(607)=.09, p=.03,95 \%$ CI $[.01, .16]$. This finding provides the strongest evidence thus far that trait self-control is somehow related to differential representations. With respect to the exact same task in all cases, individuals who were higher in trait self-control saw the task as more interesting and/or valuable. However, counter to the instrumentality prediction, this association was unaffected by the manipulation. Regressing autonomous motivation on centered trait self-control, condition, and their interaction, we found no main effect of condition, nor an interaction, $p \mathrm{~s}>.50$. (With these controls in the model, trait self-control was marginally associated with greater autonomous motivation, $b=0.14, t(605)=$ $1.76, p=.08)$. Based on this single study, we faced a lot of uncertainty about whether to interpret the absence of an experimental effect as evidence against the self-regulatory account, or simply as a failure to produce a difference in perceived instrumentality across conditions.

In hindsight, we identified several potential weaknesses in the paradigm. First, the experiential challenge of the Security Detection Task was intended to arise from the monotony. A five-trial preview may have been insufficient for making the real versus hypothetical manipulation meaningful. Second, it is possible that participants construed the dependent measure differently than we intended in the hypothetical condition. By presenting it as a task "others" would need to do, we may have unintentionally encouraged participants to simulate 
others' (or their own counterfactual) perspectives, and they may have done so relatively

accurately. With these uncertainties acknowledged, we revised the task for the next study.

\section{Study 4 Overview}

Our revision involved one key change that had a number of useful properties. Instead of a personal-relevance manipulation (real versus hypothetical task), we employed a goal-completion manipulation (ongoing versus completed task; Ferguson \& Bargh, 2004; Trope \& Fishbach, 2000). This allowed us to give participants in both conditions a richer experience of the task, while allowing more opportunity to differentiate their subjective experiences. Participants in both conditions could work on the "actual" task (rather than a preview). The motivation measure came after the same number of trials in both conditions, but in the ongoing-task condition it was partway through the task, whereas in the completed-task condition it was between the focal task and a follow-up task. Regular progress messages emphasized the difference. This change also allowed us to administer an identical measure across participants. We were able to ask, in both conditions, whether they personally perceived the task to be intrinsically interesting and/or valuable. This eliminated the potential problem of encouraging participants in the noninstrumental condition to imagine what they would have felt if it had been instrumental. We omitted a measure of controlled motivation in this study because it did not fit with the framing of the autonomous motivation measure.

\section{Method}

We recruited MTurk participants for participation in a 6-minute study $(\$ 0.61)$ on “evaluating tasks." In the end, 615 participants completed the study (268 female, 341 male, and 6 who reported non-binary responses or declined to report; $18-75$ years old, $M d n=32$ ). The computer program randomly assigned participants to the ongoing or complete condition. In the 
ongoing condition, we told participants, “Today's session will take place in 3 main parts: Part 1a $=$ UCAP Task (A), Part 1b = UCAP Task (B), Part 2 = Background Surveys." We explained that the UCAP task consisted of completing CAPTCHA tasks (i.e., typing letters from a distorted image to prove that one is a human, not a computer). In Part 1a, the participant completed three blocks of 4 CAPTCHAs each and received feedback after each block ("20\% done," "40\% done," etc.). After the third block, the participant learned that he or she was " $60 \%$ done-you still have $40 \%$ left to go." To reinforce the manipulation, the program initiated a 30 -second break, "to help you get ready to complete the rest of the UCAP Task." After the break, the participant completed the focal DV ratings. Instructions said, "Please pause to answer some questions about the UCAP Task, and then you will move on to complete the remaining $40 \%$." We asked participants to rate their agreement or disagreement with four items assessing autonomous motivation on a 7-point scale from $1=$ strongly disagree to $7=$ strongly agree. The items were "A research task like the UCAP contributes to important outcomes," "A research task like the UCAP can actually be kind of fun," "It can be interesting to work on a research task like the UCAP," and "This UCAP research task may contribute to valuable scientific findings."

In the complete condition, we tried to create the impression that the UCAP would be over after the first part of the session. Instructions stated that, “Today's session will take place in 3 main parts: The main task, then two short follow-ups: Main Task = UCAP Task, Follow-up $1=$ Brief Performance Task, Follow-up 2 = Background Surveys." We explained the UCAP in the same terms as those used in the ongoing condition. Participants then completed three blocks of 4 CAPTCHAs each, again receiving feedback after each block (“33\% done," "67\% done”). After the third block, the participant learned that he or she had completed the task. The program initiated a 30-second break. After the break, the participant completed the same focal DV ratings 
as in the ongoing condition. Instructions said, "Now that you are done with the UCAP Task, please answer some follow-up questions and then you will move on to something new."

After responding to the dependent measures, consistent with the cover story in each case, participants in the ongoing condition completed two additional blocks of CAPTCHAs, whereas participants in the complete condition completed 2 blocks of basic arithmetic questions.

Participants in both conditions ended by responding to brief demographics and the Brief SelfControl Scale $(\alpha=.87, M=3.50, S D=0.70)$.

\section{Results}

Across the two conditions, the four autonomous motivation items (important-identified, fun-intrinsic, interest-intrinsic, and value-identified $)$ were highly correlated $(\alpha=.89)$ and were averaged into a single autonomous-motivation index $(M=4.84, S D=1.37)$. For three participants who each skipped one of the items, the index is an average of three items.

We regressed autonomous motivation on centered trait self-control, condition (complete $=1$, ongoing $=0$ ), and their interaction. There was no main effect of condition, $b=0.02,95 \% \mathrm{CI}$ $[-.20, .24], \beta=0.01, t(611)=0.19, p=.85$. There was a main effect of self-control, $b=.40,95 \%$ CI $[.18, .63], \beta=0.21, t(611)=3.56, p<.001$. More importantly, this effect was qualified by a significant interaction between self-control and condition, $b=-0.36,95 \% \mathrm{CI}[-.67,-.04], \beta=-$ $0.18, t(611)=-2.25, p=.025$ (see Figure 3$).$ The simple slope of trait self-control was significant in the ongoing condition, $b=0.41,95 \% \mathrm{CI}[0.19,0.63], \beta=0.21, t=3.55, p<.001$, but not significant in the complete condition, $b=0.05,95 \%$ CI $[-0.17,0.27], \beta=0.02, t=0.45, p=.66$.

\section{Discussion}

Study 4 provides evidence that the association between trait self-control and autonomous motivation may be instrumental in nature, strengthening the self-regulatory account over other, 
more incidental accounts. Certainly, one's level of confidence in this interpretation should be tempered by the results of the precursor study, which did not find evidence that the relation depends on goal activation. However, we caution against a score-keeping approach (“one null effect, one significant effect"), or even a meta-analytic approach, when evaluating the cumulative evidence for moderation by instrumentality. Using a different manipulation, we found very different effects, suggesting that the original procedure may have been flawed. When all participants experienced the actual task and responded on identical measures, and when we adjusted the paradigm so that participants were unlikely to try to guess or simulate their motivation, we found a convincing difference between conditions. In sum, then, we take this as moderately strong evidence of an active, flexible self-regulatory account.

\section{Meta-Analysis}

To obtain a better estimate of the overall trait self-control—autonomous motivation association, we conducted an internal meta-analysis across these six studies using the R metafor package (Viechtbauer, 2010). We used Fisher's Z transformations of the raw correlations from the cross-sectional studies and experiments and used standardized coefficients as correlation coefficients for the two ESM studies (Peterson \& Brown, 2005). For Study 4P, we used the correlation from the full sample. For Study 4, given the condition effect, we only used the information obtained in the "ongoing" condition. We used the random-effects meta-analytic procedure given our small study $k$ and $\mathrm{I}^{2}$ of $61 \%$ suggesting study variability. The meta-analytic correlation coefficient $(N=2,633)$ was $0.16,95 \%$ CI $[.10, .22]$ (see Figure 4), indicative of a small but systematic association between trait self-control and autonomous motivation. 


\section{General Discussion}

Across six studies, including two experience-sampling protocols, we have documented an association between trait self-control and autonomous motivation. Across a variety of contexts and goals, people with higher versus lower levels of self-control were more likely to identify autonomous reasons for pursuing their goals. This was evident in daily life, at work and home, and in novel experimental tasks. It was evident in prospect, retrospect, and in the moment. It was evident when people ostensibly had a lot of choice over their own activities and when they were assigned to specific activities.

Across studies, we tried to balance the external validity afforded by an experiencesampling approach with the varying degrees of internal validity afforded by more controlled approaches. Experience sampling showed that the association holds in real life, but left open the possibility that higher autonomous motivation among the more self-controlled individuals was a result of choice rather than shifting motivational quality. Subsequent cross-sectional and experimental studies that employed a fixed task for all participants gave reason to favor the shifting-quality account (Studies 3, 4P, and 4). However, it is important to acknowledge that effects documented in one study cannot definitively "rule out" explanations in another study. Studies showing the association on a task that is fixed across participants provide an existence proof for the shifting-quality account, but cannot rule out the possibility that different choices at least partially contributed to the effect in experience-sampling studies.

Further, there was evidence that the relation is self-regulatory in nature. The more fatigued that people felt over the course of their workweek, the more pronounced was the association between trait self-control and autonomous motivation (Study 1), hinting that people may marshal self-control in service of autonomous motivation when needed most. Moreover, 
trait self-control only predicted autonomous motivation if people reported their reasons mid-task; it did not predict autonomous motivation if people thought they would never have to do the task again (Study 4). Thus, naturalistic and experimental evidence suggest that functionally deployed self-regulatory processes may be responsible for the boost in autonomous motivation. It does not appear to be the case that individuals higher in self-control go through life with autonomycolored glasses on. Rather, they seem to put those glasses on as needed. The basic association, and the conditions under which it is most evident, stands as preliminary, but not conclusive, evidence for a more specific causal hypothesis which states that self-control may contribute to motivational quality by increasing autonomous motivation.

We also found evidence consistent with the possibility that the positive relation between self-control and autonomous motivation has consequences for well-being. To the extent that people could identify autonomous reasons for their work, they were more satisfied with their time usage, more satisfied with their life overall, and they felt less burnt out by their circumstances. Different methods are needed to differentiate between various causal models (Fiedler et al., 2011), but the current finding adds a potential explanatory path to account for previously identified associations between trait self-control and well-being (Hofmann et al., 2014; Wiese et al., 2017). Current observations also suggest that self-control may play both a "nurturing" role, helping to increase and cultivate the positive aspects of people's goal pursuit, and a "protective" role, helping to buffer against the stress and conflict that often characterize challenging, long-term goal pursuit.

\section{Causality and Other Open Questions}

While the moderation evidence, especially the experimental moderation in Study 4, disposes us to favor the interpretation that self-control affects autonomous motivation, the 
current work clearly has not provided direct causal evidence for this claim. The possibility of reverse causation merits serious consideration. It is possible that more frequently experiencing high autonomous motivation causes people to report that they are better at self-control. Over a longer timescale, it is reasonable that someone who regularly found himself pursuing what he saw as interesting and meaningful work would tend to be more successful in his work. He would more readily agree, for instance, that he "[is] able to work effectively toward long-term goals," and disagree that he "[has] trouble concentrating" (Tangney et al., 2004). At least in the longterm, then, there is a possible path by which individual differences in autonomous functioning could cause what is interpreted as self-controlled behavior. However, this story only seems compelling over a longer time horizon. The moderation effects demonstrated in Studies 1 and 4 render this causal direction less plausible, in our evaluation, because it is harder to explain how a short-term need to engage autonomous motivation would cause variation in reports of trait selfcontrol. If the relation between trait self-control and autonomous motivation can be "turned down" when people are relatively more energized (Study 1) or disengaged from the task (Study 4), it seems likelier that the enactment of self-control processes is the causal agent. Taking stock of the full set of evidence, we have not established a definitive case for the causal role of selfcontrol, but we have gone beyond the initial step of merely documenting an association.

Another open question for future research involves identifying the specific processes that link self-control and autonomous motivation. We suggest that three models stand out as most promising for future investigation. The first candidate, which we refer to as a "representational model," builds from the idea that self-control can support goal pursuit by modulating representations of goal-relevant stimuli (see Fishbach \& Converse, 2010; Kuhl, 1984; Mischel et al., 1989). Even without effortful, conscious control, self-regulation can support goal pursuit by 
leading people to cognitively represent goal-related stimuli in positive ways (e.g., Ferguson \& Bargh, 2004; Fishbach et al., 2010). It is possible that self-control similarly operates on motivational quality by influencing how people attend to, encode, retrieve, or interpret their reasons for goal pursuit.

A second candidate is a "desire-competition model." This model builds from the premise that trait self-control reflects, to a large extent, the meta-trait of stability, a tendency toward restraint and lack of emotional and motivational disruption (DeYoung, 2011; Olson, 2005; Tangney et al., 2004). Consistent with this notion, individuals who are higher (versus lower) in trait self-control experience tempting desires less frequently and less strongly (Hofmann et al., 2012; Imhoff et al., 2014), possibly because they experience temptations as less alluring in the first place and possibly because they down-regulate the allure more quickly (Gillebaart et al., 2015; Hofmann, Friese, \& Strack, 2009; Myrseth, Fishbach, \& Trope, 2009). This raises the possibility that those who are lower in self-control feel less autonomous motivation because they are feeling a stronger pull to do something else instead. This argument requires an additional assumption, namely that tempting alternatives detract from the experience of autonomous motivation-in other words, that there is some competition between the strength of competing desires and autonomous motivation—but represents an intriguing possibility.

A third candidate model has roots in self-perception theory (Bem, 1972). It starts from the premise that individuals who are higher in trait self-control rely more on beneficial habits (Adriaanse et al., 2014; Galla \& Duckworth, 2015). Considering that habits are automatic responses to cuing situations (Wood \& Neal, 2007), when individuals are asked to report on their reasons for pursuing a habitual action, they may find it difficult to identify any attribution for their own behavior. In the absence of strong external cues, which can more readily be observed, 
individuals acting out of habit may be likelier to arrive at an internal attribution for their motivated behavior (e.g., Lepper, 1973; Lepper \& Greene, 1975). In short, if an individual is prompted to assess the quality of her motivation, but she does not know why she is pursuing a goal, she may be more likely to infer that she must be pursuing it for intrinsic reasons. This process seems unlikely to account for the results of Study 4, but the field results from Studies 1 and $1 \mathrm{R}$ especially are likely to be multiply determined and this could be one contributor.

Indeed, the current research prompts at least as many questions as answers. Future studies might benefit from a long-term longitudinal approach that allows tracking of changes in trait self-control, from the addition of measures of dispositional autonomy (e.g., Weinstein et al., 2012), and from paradigms that allow for the targeted examination of potential mechanisms.

\section{Theoretical Implications}

With outstanding questions acknowledged, we offer that the current work already suggests a number of theoretical and practical implications. Most of all, this work builds a bridge between two major areas of self-regulation research, self-control and self-determination, that rarely intersect. Our work hints at the possibility that the quality of motivation, a key determinant of goal-pursuit success and more general need fulfillment and well-being, may itself be determined not just by features of the task and situation, but also by self-control processes initiated by the individual. With respect to self-determination theory, this work highlights and provides initial empirical support for a mostly overlooked potential cause of motivation quality.

With respect to self-control, this work makes a few distinct contributions. First, the work contributes to an ongoing discussion about the relation between trait- and state-self-control (e.g., Baumeister et al., 2007; de Ridder et al., 2012; DeWall et al., 2007; Imhoff et al., 2014; Milyavskaya \& Inzlicht, 2017; Muraven et al., 2007). By documenting systematic situational 
variation in the association between trait self-control and autonomous motivation, we provided some support for the view that trait self-control is a marker of one's likelihood or ability to engage helpful self-control processes when needed. Moreover, our work bolsters an emerging view that trait self-control involves a substantial proactive component. Given the variety of contexts in which we documented the association, it appears that self-control is not solely involved in overcoming tempting impulses - it also plays a general role in improving the circumstances of goal pursuit. Our work also extends the proactive view by documenting a new proactive mechanism. Previous work has focused on how self-control makes goal pursuit easier by helping people to avoid temptations in the first place, or by inflating the desirability of the end-state. Identifying autonomous reasons for one's work, and thereby increasing the extent to which one's efforts are autonomously regulated, is a third proactive path.

Finally, we believe this work contributes to a "whole trait" view of self-control by helping to identify the explanatory part of the trait (Fleeson \& Jayawickreme, 2015). At this point, both the concurrent and predictive validity of trait self-control are extremely wellestablished (de Ridder et al., 2012; Duckworth \& Kern, 2011). The current work adds to a growing effort to enumerate the specific behavioral and social-cognitive mechanisms through which self-control so profoundly affects outcomes (e.g., Adriaanse et al., 2014; Ent et al., 2015; Hofmann et al., 2012). By drawing from needs-based models of motivation (Deci \& Ryan, 2000; see also Dweck, 2017), we were able to focus attention on motivation quality as another potentially influential mechanism.

\section{Practical Implications}

Sometimes the conditions of goal pursuit are less than ideal for cultivating autonomous motivation. Even individuals with lots of objective control over their to-dos at work and home 
are not always able to choose the more interesting task or set up the optimal situation. Sometimes students do have to focus on making the grade rather than pursuing personal edification. Sometimes employees have to recognize that the boss is watching closely, ready with rewards or punishments in hand. It should be reassuring, then, for those who are higher in self-control, that self-control seems to be involved in recognizing the interesting features or higher-level meaning of one's work. At the same time, it should serve as a warning to those lower in self-control, and those managing them or living with them, that they may be less likely to do the same. Thirdparties who are trying to help may need to more actively shape the situation appropriately for these individuals, emphasizing freedoms more, providing more opportunities for novelty, and helping to promote the connection to higher-level meaning (Harackiewicz \& Hulleman, 2009; Reeve, 2009).

This work also prompts a provocative applied question: Is it possible that individuals could train themselves, or be trained by others, to regulate their goal pursuit in more intrinsic or identified ways? Perhaps through education, practice, and/or therapy, individuals could learn to identify autonomous reasons, therefore changing the quality of their own motivation, and prompting more beneficial modes of self-regulation. Simple prompts can lead individuals to focus on what is fun in their work (Sansone et al., 1992) or help them to see how the work is valuable for their own and others' outcomes (Hulleman, Godes, Hendricks, \& Harackiewicz, 2010; Hulleman \& Harackiewicz, 2009; Yeager et al., 2014). Perhaps, in concert with improved self-control, individuals could develop the ability to easily adopt such a perspective on their own.

\section{Conclusion}

Most people are hungry to pursue interesting work and make meaningful contributions. Access to inherently interesting tasks and exposure to autonomy-supportive situations certainly 
promote such an experience, but people do not always have the luxury of such optimal goalpursuit conditions. The current work hints that self-control may play a role as well, which would be particularly valuable for the self-controlled person who happens to be stuck in otherwise uninspiring circumstances. Underlying reasons matter a great deal for goal-pursuit outcomes, and self-control may help individuals tap into the most advantageous of those reasons. 


\section{References}

Aarts, H., Dijksterhuis, A., \& Vries, P. (2001). On the psychology of drinking: Being thirsty and perceptually ready. British Journal of Psychology, 92, 631-642.

Abler, B., \& Kessler, H. (2009). Emotion Regulation Questionnaire-Eine deutschsprachige Fassung des ERQ von Gross und John. Diagnostica, 55, 144-152.

Adriaanse, M. A., Kroese, F. M., Gillebaart, M., \& de Ridder, D. T. (2014). Effortless inhibition: Habit mediates the relation between self-control and unhealthy snack consumption. Frontiers in Psychology, 5, 1-6.

Anderson, C., \& Galinsky, A. D. (2006). Power, optimism, and risk-taking. European Journal of Social Psychology, 36, 511-536.

Ariely, D. \& Wertenbroch, K. (2002). Procrastination, deadlines, and performance: Self-control by precommitment. Psychological Science, 13, 219-224.

Bandura, A., \& Schunk, D. H. (1981). Cultivating competence, self-efficacy, and intrinsic interest through proximal self-motivation. Journal of Personality and Social Psychology, $41,586-598$.

Barr, D. J., Levy, R., Scheepers, C., \& Tily, H. J. (2013). Random effects structure for confirmatory hypothesis testing: Keep it maximal. Journal of Memory and Language, 68, 255-278.

Bates, D., Maechler, M., Bolker, B. \& Walker, S. (2015). Fitting linear mixed-effects models using lme4. Journal of Statistical Software, 67, 1-48.

Baumeister, R. F., Bratslavsky, E., Muraven, M., \& Tice, D. M. (1998). Ego depletion: Is the active self a limited resource? Journal of Personality and Social Psychology, 74, 12521265. 
Baumeister, R. F., Heatherton, T. F., \& Tice, D. M. (1994). Losing control: How and why people fail at self-regulation. San Diego: Academic.

Baumeister, R. F., Vohs, K. D., \& Tice, D. M. (2007). The strength model of selfcontrol. Current Directions in Psychological Science, 16, 351-355.

Bem, D. J. (1972). Self-perception theory. Advances in Experimental Social Psychology, 6, 1-62.

Bénabóu, R., \& Tirole, J. (2003). Intrinsic and extrinsic motivation. The Review of Economic Studies, 70, 489-520.

Bertrams, A., \& Dickhäuser, O. (2009). High-school students' need for cognition, self-control capacity, and school achievement: Testing a mediation hypothesis. Learning and Individual Differences, 19, 135-138.

Bertrams, A., \& Dickhäuser, O. (2009). Messung dispositioneller Selbstkontroll-Kapazität: Eine deutrait self-controlhe Adaptation der Kurzform der Self-Control Scale (SCSKD). Diagnostica, 55, 2-10.

Black, A. E., \& Deci, E. L. (2000). The effects of instructors' autonomy support and students' autonomous motivation on learning organic chemistry: A self-determination theory perspective. Science Education, 84, 740-756.

Bluedorn, A. C., Kalliath, T. J., Strube, M. J., \& Martin, G. D. (1999). Polychronicity and the Inventory of Polychronic Values (IPV) The development of an instrument to measure a fundamental dimension of organizational culture. Journal of Managerial Psychology, 14, 205-231.

Boggiano, A. K., Flink, C., Shields, A., Seelbach, A., \& Barrett, M. (1993). Use of techniques promoting students' self-determination: Effects on students' analytic problem-solving skills. Motivation and Emotion, 17, 319-336. 
Borritz, M., Bültmann, U., Rugulies, R., Christensen, K. B., Villadsen, E., \& Kristensen, T. S. (2005). Psychosocial work characteristics as predictors for burnout: findings from 3-year follow up of the PUMA Study. Journal of Occupational and Environmental Medicine, 47, 1015-1025.

Boyle, P. A., Buchman, A. S., Barnes, L. L., James, B. D., \& Bennett, D. A. (2010). Association between life space and risk of mortality in advanced age. Journal of the American Geriatrics Society, 58, 1925-1930.

Brandtstädter, J., \& Renner, G. (1990). Tenacious goal pursuit and flexible goal adjustment: Explication and age-related analysis of assimilative and accommodative strategies of coping. Psychology and Aging, 5, 58-67.

Bundick, M. J. (2011). The benefits of reflecting on and discussing purpose in life in emerging adulthood. New Directions for Student Leadership, 2011, 89-103.

Burke, M. J., Brief, A. P., George, J. M., Roberson, L., \& Webster, J. (1989). Measuring affect at work: Confirmatory analyses of competing mood structures with conceptual linkage to cortical regulatory systems. Journal of Personality and Social Psychology, 57, 10911102.

Carver, C. S., \& White, T. L. (1994). Behavioral inhibition, behavioral activation, and affective responses to impending reward and punishment: The BIS/BAS Scales. Journal of Personality and Social Psychology, 67, 319.

Chandler, J. J., \& Paolacci, G. (2017). Lie for a dime: When most prescreening responses are honest but most "eligible" respondents are lies. Social Psychological and Personality Science, 8, 1-9. 
Cialdini, R. B., Trost, M. R., \& Newsom, J. T. (1995). Preference for consistency: The development of a valid measure and the discovery of surprising behavioral implications. Journal of Personality and Social Psychology, 69, 318.

Clark, M. S., Oullette, R., Powell, M. C., \& Milberg, S. (1987). Recipient's mood, relationship type, and helping. Journal of Personality and Social Psychology, 53, 94-103.

Cooper, J., \& Fazio, R. H. (1984). A new look at dissonance theory. Advances in Experimental Social Psychology, 17, 229-266.

Czikmantori, T., Hennecke, M., \& Brandstätter, V. (2015). Dispositional taking pleasure. Unpublished manuscript, Department of Psychology, University of Zurich, Switzerland.

Danner, F., \& Lonky, E. (1981). A cognitive-developmental approach to the effects of rewards on intrinsic motivation. Child Development, 52, 1043-1052.

de Ridder, D. T., Lensvelt-Mulders, G., Finkenauer, C., Stok, F. M., \& Baumeister, R. F. (2012). Taking stock of self-control: A meta-analysis of how trait self-control relates to a wide range of behaviors. Personality and Social Psychology Review, 16, 76-99.

Deci, E. L. (1975). Intrinsic motivation. New York: Plenum.

Deci, E. L., Connell, J. P., \& Ryan, R. M. (1989). Self-determination in a work organization. Journal of Applied Psychology, 74, 580-590.

Deci, E.L., Eghrari, H., Patrick, B.C., \& Leone, D.R. (1994). Facilitating internalization: The self-determination theory perspective. Journal of Personality, 62, 119-142.

Deci, E. L., Koestner, R., \& Ryan, R. M. (1999). A meta-analytic review of experiments examining the effect of extrinsic rewards on intrinsic motivation. Psychological Bulletin, $125,627-688$. 
Deci, E. L., \& Ryan, R. M. (1985). The general causality orientations scale: Self-determination in personality. Journal of Personality and Social Psychology, 19, 109-134.

Deci, E. L., \& Ryan, R. M. (2000). The "what" and "why" of goal pursuits: Human needs and the self-determination of behavior. Psychological Inquiry, 11, 227-268.

Deci, E. L., \& Ryan, R. M. (2012). Motivation, personality, and development within embedded social contexts: An overview of self-determination theory. In R. M. Ryan (Ed.), The Oxford handbook of human motivation (pp. 85-107). Oxford, England: Oxford University Press.

Diefendorff, J. M., Hall, R. J., Lord, R. G., \& Strean, M. L. (2000). Action-state orientation: Construct validity of a revised measure and its relationship to work-related variables. Journal of Applied Psychology, 85, 250-263.

Diener, E. D., Emmons, R. A., Larsen, R. J., \& Griffin, S. (1985). The satisfaction with life scale. Journal of Personality Assessment, 49, 71-75.

Diener, E., Wirtz, D., Tov, W., Kim-Prieto, C., Choi, D. W., ... Biswas-Diener, R. (2010). New well-being measures: Short scales to assess flourishing and positive and negative feelings. Social Indicators Research, 97, 143-156.

DeYoung, C. G. (2011). Impulsivity as a personality trait. In K. D. Vohs \& R. F. Baumeister (Eds.), Handbook of self-regulation: Research, theory, and applications (pp.485-502). New York: Guilford.

Diener, E. D., Emmons, R. A., Larsen, R. J., \& Griffin, S. (1985). The satisfaction with life scale. Journal of Personality Assessment, 49, 71-75.

Duckworth, A. L., \& Kern, M. L. (2011). A meta-analysis of the convergent validity of selfcontrol measures. Journal of Research in Personality, 45, 259-268. 
Duckworth, A. L., Gendler, T. S., \& Gross, J. J. (2016). Situational strategies for selfcontrol. Perspectives on Psychological Science, 11, 35-55.

Dweck, C. S. (2017). From needs to goals and representations: Foundations for a unified theory of motivation, personality, and development. Psychological Review, 124, 689-719.

Dweck, C. S., \& Leggett, E. L. (1988). A social-cognitive approach to motivation and personality. Psychological Review, 95, 256-273.

Elliot, A. J., \& McGregor, H. A. (2001). A 2× 2 achievement goal framework. Journal of Personality and Social Psychology, 80, 501-519.

Ent, M. R., Baumeister, R. F., \& Tice, D. M. (2015). Trait self-control and the avoidance of temptation. Personality and Individual Differences, 74, 12-15.

Erdvik, I. B., Øverby, N. C., \& Haugen, T. (2014). Students' self-determined motivation in physical education and intention to be physically active after graduation: The role of perceived competence and identity. Journal of Physical Education and Sport, 14, 232241.

Ferguson, M. J., \& Bargh, J. A. (2004). Liking is for doing: the effects of goal pursuit on automatic evaluation. Journal of Personality and Social Psychology, 87, 557-572.

Festinger, L. A. (1957). A Theory of Cognitive Dissonance. Stanford, CA: Stanford University Press.

Fiedler, K., Schott, M., \& Meiser, T. (2011). What mediation analysis can (not) do. Journal of Experimental Social Psychology, 47, 1231- 1236. 
Fishbach, A., \& Converse, B. A. (2010). Walking the line between goals and temptations: Asymmetric effects of counteractive control. In R. R. Hassin, K. N. Ochsner, \& Y. Trope (Eds.), Self control in society, mind, and brain (pp. 389-407). New York: Oxford University Press.

Fishbach, A., \& Converse, B. A. (2011). Identifying and battling temptation. In K. D. Vohs \& R. F. Baumeister (Eds.), Handbook of self-regulation: Research, theory and applications (pp. 244-260). New York: Guilford Press.

Fishbach, A., Friedman, R. S., \& Kruglanski, A. W. (2003). Leading us not into temptation: Momentary allurements elicit overriding goal activation. Journal of Personality and Social Psychology, 84, 296-309.

Fishbach, A., Shah, J. Y., \& Kruglanski, A. (2004). Emotional transfer in goal systems. Journal of Experimental Social Psychology, 40, 723-738.

Fishbach, A., Zhang, Y., \& Trope, Y. (2010). Counteractive evaluation: Asymmetric shifts in the implicit value of conflicting motivations. Journal of Experimental Social Psychology, 46, 29-38.

Fleeson, W. (2001). Toward a structure-and process-integrated view of personality: Traits as density distributions of states. Journal of Personality and Social Psychology, 80, 10111027.

Fleeson, W., \& Jayawickreme, E. (2015). Whole trait theory. Journal of Research in Personality, $56,82-92$.

Förster, J., Liberman, N., \& Friedman, R. S. (2007). Seven principles of goal activation: A systematic approach to distinguishing goal priming from priming of non-goal constructs. Personality and Social Psychology Review, 11, 211-233. 
Freitas, A. L., Gollwitzer, P., \& Trope, Y. (2004). The influence of abstract and concrete mindsets on anticipating and guiding others' self-regulatory efforts. Journal of Experimental Social Psychology, 40, 739-752.

Freitas, A. L., Salovey, P., \& Liberman, N. (2001). Abstract and concrete self-evaluative goals. Journal of Personality and Social Psychology, 80, 410-424.

Frost, R. O., Marten, P., Lahart, C., \& Rosenblate, R. (1990). The dimensions of perfectionism. Cognitive Therapy and Research, 14, 449-468.

Fujita, K. (2011). On conceptualizing self-control as more than the effortful inhibition of impulses. Personality and Social Psychology Review, 15, 352-366.

Fujita, K., \& Han, H. A. (2009). Moving beyond deliberative control of impulses the effect of construal levels on evaluative associations in self-control conflicts. Psychological Science, 20, 799-804.

Fujita, K., Trope, Y., Liberman, N., \& Levin-Sagi, M. (2006). Construal levels and selfcontrol. Journal of Personality and Social Psychology, 90, 351-367.

Gagné, M., \& Deci, E. L. (2005). Self-determination theory and work motivation. Journal of Organizational Behavior, 26, 331-362.

Galla, B. M., \& Duckworth, A. L. (2015). More than resisting temptation: Beneficial habits mediate the relationship between self-control and positive life outcomes. Journal of Personality and Social Psychology, 109, 508-525.

Gillebaart, M., Schneider, I. K., \& de Ridder, D. T. (2015). Effects of trait self-control on response conflict about healthy and unhealthy food. Journal of Personality, 84, 789-798.

Gosling, S. D., Rentfrow, P. J., \& Swann, W. B. (2003). A very brief measure of the Big-Five personality domains. Journal of Research in Personality, 37, 504-528. 
Grolnick, W. S., \& Ryan, R. M. (1987). Autonomy in children's learning: An experimental and individual difference investigation. Journal of Personality and Social Psychology, 52, 890-898.

Gross, J. J., \& John, O. P. (2003). Individual differences in two emotion regulation processes: Implications for affect, relationships, and well-being. Journal of Personality and social Psychology, 85, 348-362.

Hackman, J. R., \& Oldham, G. R. (1976). Motivation through the design of work: Test of a theory. Organizational Behavior and Human Performance, 16, 250-279.

Harackiewicz, J. M., \& Elliot, A. J. (1998). The joint effects of target and purpose goals on intrinsic motivation: A mediational analysis. Personality and Social Psychology Bulletin, 24, 675-689.

Harackiewicz, J. M. \& Hulleman, C. S. (2009). The importance of interest: The role of achievement goals and task values in promoting the development of interest. Social and Personality Psychology Compass, 4, 42-52.

Harackiewicz, J. M., Manderlink, G., \& Sansone, C. (1984). Rewarding pinball wizardry: effects of evaluation and cue value on intrinsic interest. Journal of Personality and Social Psychology, 47, 287-300.

Harackiewicz, J. M., \& Sansone, C. (1991). Goals and intrinsic motivation: You can get there from here. In M. L. Maehr \& P. R. Pintrich (Eds.), Advances in motivation and achievement: Goals and self-regulatory processes (Vol. 7, pp. 21-49). Greenwich, CT: JAI Press. 
Hennecke, M., Czikmantori, T., \& Brandstätter, V. (2018). Doing despite disliking: Selfregulatory strategies in everyday aversive goal pursuit. Manuscript submitted for publication.

Hofmann, W., Baumeister, R. F., Förster, G., \& Vohs, K. D. (2012). Everyday temptations: an experience sampling study of desire, conflict, and self-control. Journal of Personality and Social Psychology, 102, 1318-1335.

Hofmann, W., Friese, M., \& Strack, F. (2009). Impulse and self-control from a dual-systems perspective. Perspectives on Psychological Science, 4(2), 162-176

Hofmann, W., Luhmann, M., Fisher, R. R., Vohs, K. D., \& Baumeister, R. F. (2014). Yes, but are they happy? Effects of trait self-control on affective well-being and life satisfaction. Journal of Personality, 82, 265-277.

Hofmann, W., \& Patel, P. V. (2015). SurveySignal: A convenient solution for experience sampling research using participants' own smartphones. Social Science Computer Review, 33, 235-253.

Hofmann, W., Vohs, K. D., \& Baumeister, R. F. (2012). What people desire, feel conflicted about, and try to resist in everyday life. Psychological Science, 23, 582-588.

Howard, J. L., Gagné, M., \& Bureau, J. S. (2017). Testing a continuum structure of selfdetermined motivation: A meta-analysis. Psychological Bulletin, http://dx.doi.org/10.1037/bul0000125

Hulleman, C. S., Godes, O., Hendricks, B. L., \& Harackiewicz, J. M. (2010). Enhancing interest and performance with a utility value intervention. Journal of Educational Psychology, 102, 880-895. 
Hulleman, C. S., \& Harackiewicz, J. M. (2009). Promoting interest and performance in high school science classes. Science, 326, 1410-1412.

Imhoff, R., Schmidt, A. F., \& Gerstenberg, F. (2014). Exploring the interplay of trait self-control and ego depletion: Empirical evidence for ironic effects. European Journal of Personality, 28, 413-424.

Inzlicht, M., \& Schmeichel, B. J. (2012). What is ego depletion? Toward a mechanistic revision of the resource model of self-control. Perspectives on Psychological Science, 7, 450-463.

Job, V., Dweck, C. S., \& Walton, G. M. (2010). Ego depletion-Is it all in your head? Implicit theories about willpower affect self-regulation. Psychological Science, 21, 1686-1693.

John, O. P., Donahue, E. M., \& Kentle, R. L. (1991). The Big Five Inventory -Versions 4a and 54. Berkeley, CA: University of California, Berkeley, Institute of Personality and Social Research.

Judge, T. A., Bono, J. E., Erez, A., Locke, E. A. (2005). Core self-evaluations and job and life satisfaction: The role of self-concordance and goal attainment. Journal of Applied Psychology, 90, 257-268.

Kahneman, D., Krueger, A. B., Schkade, D. A., Schwarz, N., \& Stone, A. A. (2004). A survey method for characterizing daily life experience: The day reconstruction method. Science, 306, 1776-1780.

Koestner, R., Otis, N., Powers T. A., Pelletier L., Gagnon H. (2008). Autonomous motivation, controlled motivation, and goal progress. Journal of Personality, 76, 1201-1230.

Koestner, R., Ryan, R. M., Bernieri, F., \& Holt, K. (1984). Setting limits on children's behavior: The differential effects of controlling vs. informational styles on intrinsic motivation and creativity. Journal of Personality, 52, 233-248. 
Kristensen, T. S., Borritz, M., Villadsen, E., \& Christensen, K. B. (2005). The Copenhagen Burnout Inventory: A new tool for the assessment of burnout. Work \& Stress, 19, 192207.

Kross, E., Ayduk, O., \& Mischel, W. (2005). When asking "why” does not hurt distinguishing rumination from reflective processing of negative emotions. Psychological Science, 16, 709-715.

Kruglanski, A. W., Shah, J. Y., Fishbach, A., Friedman, R., Chun, W. Y., \& Sleeth-Keppler, D. (2002). A theory of goal systems. In M. P. Zanna (Ed.), Advances in experimental social psychology (Vol. 34, pp. 331-378). New York: Academic Press.

Kuhl, J. (1984). Volitional aspects of achievement motivation and learned helplessness: Toward a comprehensive theory of action control. In B. A. Mahler (Ed.), Progress in experimental personality research (Vol. 13, pp. 99-171). NY: Academic Press.

Kuhl, J. (1990). Kurzanweisung zum Fragebogen HAKEMP 90. Manuskript. Fachbereich Psychologie, Universität Osnabrück.

Kuhl, J., \& Fuhrmann, A. (2004). Self-regulation Inventory SSI-K3 (short version). Scoring key. Unpublished material, Universität Osnabrück, Osnabrück.

Lake, C. J., Gopalkrishnan, P., Sliter, M. T., \& Withrow, S. (2010). The Job Descriptive Index: Newly updated and available for download. The Industrial-Organizational Psychologist, 48, 47-49.

Laran, J., \& Janiszewski, C. (2010). Work or fun? How task construal and completion influence regulatory behavior. Journal of Consumer Research, 37, 967-983.

Lepper, M. R. (1973). Dissonance, self-perception, and honesty in children, Journal of Personality and Social Psychology, 25, 65-74. 
Lepper, M. R., \& Greene, D. (1975). Turning play into work: Effects of adult surveillance and extrinsic rewards on children's intrinsic motivation. Journal of Personality and Social Psychology, 31, 479-486.

Loewenstein, G. (1996). Out of control: Visceral influences on behavior. Organizational Behavior \& Human Decision Processes, 65, 272-292.

MacGregor, K. E., Carnevale, J. J., Dusthimer, N. E., \& Fujita, K. (2017). Knowledge of the self-control benefits of high-level versus low-level construal. Journal of Personality and Social Psychology, 112, 607-620.

Markman, A. B., \& Brendl, C. M. (2000). The influence of goals on value and choice. Psychology of Learning and Motivation, 39, 97-128.

Marsh, R. L., Hicks, J. L., \& Bryan, E. S. (1999). The activation of unrelated and canceled intentions. Memory \& Cognition, 27, 320-327.

Maslach, C., Schaufeli, W. B., \& Leiter, M. P. (2001). Job burnout. Annual Review of Psychology, 52, 397-422.

McCabe, K. O., \& Fleeson, W. (2016). Are traits useful? Explaining trait manifestations as tools in the pursuit of goals. Journal of Personality and Social Psychology, 110, 287-301.

Metcalfe, J., \& Mischel, W. (1999). A hot/cool-system analysis of delay of gratification: dynamics of willpower. Psychological Review, 106, 3-19.

Milkman, K. L., Rogers, T., \& Bazerman, M. H. (2008). Harnessing our inner angels and demons: What we have learned about want/should conflicts and how that knowledge can help us reduce short-sighted decision making. Perspectives on Psychological Science, 3, 324-338. 
Milyavskaya, M. \& Inzlicht, M. (2017). What's so great about self-control? Examining the importance of effortful self-control and temptation in predicting real-life depletion and goal attainment. In press at Social Psychological and Personality Science.

Milyavskaya, M., Inzlicht, M., Hope, N., \& Koestner, R. (2015). Saying 'no' to temptation: Want-to motivation improves self-regulation by reducing temptation rather than by increasing self-control. Journal of Personality and Social Psychology, 109, 677-693.

Milyavskaya, M., Nadolny, D., \& Koestner, R. (2014). Where do self-concordant goals come from? The role of domain-specific psychological need satisfaction. Personality and Social Psychology Bulletin, 40, 700-711.

Mischel, W., \& Ayduk, O. (2004). Willpower in a cognitive-affective processing system. In R. F. Baumeister \& K. D. Vohs (Eds.), Handbook of self-regulation: Research, theory, and applications. (pp. 99-129). New York: Guilford Press.

Mischel, W. \& Baker, N. (1975). Cognitive appraisals and transformations in delay behavior. Journal of Personality and Social Psychology, 31, 254-261.

Mischel, W., Shoda, Y., \& Rodriguez, M. L. (1989). Delay of gratification in children. Science, 244, 933-938.

Moors, A., De Houwer, J., \& Eelen, P. (2004). Automatic stimulus-goal comparisons: Support from motivational affective priming studies. Cognition and Emotion, 18, 29-54.

Muraven, M., Gagné, M., \& Rosman, H. (2008). Helpful self-control: Autonomy support, vitality, and depletion. Journal of Experimental Social Psychology, 44, 573-585.

Muraven, M., Rosman, H., \& Gagné, M. (2007). Lack of autonomy and self-control: Performance contingent rewards lead to greater depletion. Motivation and Emotion, 31, 322-330. 
Muraven, M., Shmueli, D., \& Burkley, E. (2006). Conserving self-control strength. Journal of Personality and Social Psychology, 91, 524-537.

Myrseth, K. O. R., Fishbach, A., \& Trope, Y. (2009). Counteractive self-control: When making temptation available makes temptation less tempting. Psychological Science, 20(2), 159163.

Ng, J. Y. Y., Ntoumanis, N., Thogersen-Ntoumani, C., Deci, E. L., Ryan, R. M., ... Williams, G. C. (2012). Self-determination theory applied to health contexts: A meta-analysis. Perspectives on Psychological Science, 7, 325-340.

Nicholls, J. G. (1984). Achievement motivation: Conceptions of ability, subjective experience, task choice, and performance. Psychological Review, 91, 328-346.

Nix, G. A., Ryan, R. M., Manly, J. B., \& Deci, E. L. (1999). Revitalization through selfregulation: The effects of autonomous and controlled motivation on happiness and vitality. Journal of Experimental Social Psychology, 35, 266-284.

Olson, K. R. (2005). Engagement and self-control: Superordinate dimensions of Big Five traits. Personality and Individual Differences, 38, 1689-1700.

Patton, J. H., \& Stanford, M. S. (1995). Factor structure of the Barratt impulsiveness scale. Journal of Clinical Psychology, 51, 768-774.

Pavot, W., \& Diener, E. (2008). The satisfaction with life scale and the emerging construct of life satisfaction. The Journal of Positive Psychology, 3, 137-152.

Peterson, R. A., \& Brown, S. P. (2005). On the use of beta coefficients in meta-analysis. Journal of Applied Psychology, 90, 175-181.

Rammstedt, B., \& John, O. P. (2005). Kurzversion des Big Five Inventory (BFI-K). Diagnostica, 51, 195-206. 
R Core Team (2016). R: A language and environment for statistical computing. R Foundation for Statistical Computing, Vienna, Austria. https://www.R-project.org/

Reeve, J. (2009). Why teachers adopt a controlling motivating style toward students and how they can become more autonomy supportive. Educational Psychologist, 44, 159-175.

Reeve, J., Deci, E. L., \& Ryan, R. M. (2004). Self-determination theory: A dialectical framework for understanding sociocultural influences on student. In D. M. McInerney \& S. Van Etten (Eds.), Research on sociocultural influences on motivation and learning: Big theories revisited (Vol. 4, pp. 31-59). Greenwich, CT: Information Age Press.

Roediger III, H. L. (1996). Memory illusions. Journal of Memory and Language, 35, 76-100.

Roets, A., \& Van Hiel, A. (2007). Separating ability from need: Clarifying the dimensional structure of the need for closure scale. Personality and Social Psychology Bulletin, 33, 266-280.

Rogers, T. \& Bazerman, M. H. (2008). Future lock-in: Future implementation increases selection of 'should' choices. Organizational Behavior and Human Decision Processes, 106, 1-20.

Ryan, R. M. (1995). Psychological needs and the facilitation of integrative processes. Journal of Personality, 63, 397-427.

Ryan, R. M. \& Deci, E. L. (2000). Self-determination theory: Facilitation of intrinsic motivation, social development, and well-being. American Psychologist, 55, 68-78.

Ryan, R. M., Deci, E. L., \& Vansteenkiste, M. (2016). Autonomy and autonomy disturbances in self-development and psychopathology: Research on motivation, attachment, and clinical process. In D. Cicchetti (Ed.), Developmental psychopathology ( $3^{\text {rd }}$ ed., pp. 385-438). London, England: Wiley. 
Ryan, R. M., \& Frederick, C. (1997). On energy, personality, and health: Subjective vitality as a dynamic reflection of well-being. Journal of Personality, 65, 529-565.

Ryff, C. D. (1989). Happiness is everything, or is it? Explorations on the meaning of psychological well-being. Journal of Personality and Social Psychology, 57, 1069-81.

Sansone, C., Thoman, D. B., \& Smith, J. L. (2010). Interest and self-regulation: Understanding individual variability in choices, efforts, and persistence over time. In R. Hoyle (Ed.), Handbook of personality and self-regulation (pp. 192-217). Malden, MA: Blackwell.

Sansone, C., Weir, C., Harpster, L., \& Morgan, C. (1992). Once a boring task always a boring task? Interest as a self-regulatory mechanism. Journal of Personality and Social Psychology, 63, 379-390.

Sansone, C., Wiebe, D. J., \& Morgan, C. (1999). Self-regulating interest: The moderating role of hardiness and conscientiousness. Journal of Personality, 67, 701-733.

Schallberger, U. (2005). Kurzskalen zur Erfassung der Positiven Aktivierung, Negativen Aktivierung und Valenz in Experience Sampling Studien (PANAVA-KS). Theoretische und methodische Grundlagen, Konstruktvalidität und psychometrische Eigenschaften bei der Beschreibung intra-und interindividueller Unterschiede.

Schelling, T. C. (1984). Self-Command in Practice, in Policy, and in a Theory of Rational Choice. American Economic Review, 74, 1-11.

Schmeichel, B. J., Vohs, K. D., \& Baumeister, R. F. (2003). Intellectual performance and ego depletion: role of the self in logical reasoning and other information processing. Journal of Personality and Social Psychology, 85, 33-46. 
Schultheiss, O. C., Yankova, D., Dirlikov, B., \& Schad, D. J. (2009). Are implicit and explicit motive measures statistically independent? A fair and balanced test using the Picture Story Exercise and a cue-and response-matched questionnaire measure. Journal of Personality Assessment, 91, 72-81.

Schumacher, J., Klaiberg, A., \& Brähler, E. (2003). Diagnostik von Lebensqualität und Wohlbefinden-Eine Einführung. In Diagnostische Verfahren zu Lebensqualität und Wohlbefinden. Göttingen: Hogrefe (pp. 9-24).

Shah, J. Y., Friedman, R., \& Kruglanski, A. W. (2002). Forgetting all else: on the antecedents and consequences of goal shielding. Journal of Personality and Social Psychology, 83, 1261-1280.

Sheldon, K. M., \& Elliot, A. J. (1998). Not all personal goals are personal: Comparing autonomous and controlled reasons for goals as predictors of effort and attainment. Personality and Social Psychology Bulletin, 24, 546-557.

Sheldon, K. M., \& Elliot, A. J. (1999). Goal striving, need satisfaction, and longitudinal wellbeing: the self-concordance model. Journal of Personality and Social Psychology, 76, $482-497$.

Sheldon, K. M., Houser-Marko, L. (2001). Self-concordance, goal attainment, and the pursuit of happiness: can there be an upward spiral? Journal of Personality and Social Psychology, $80,152-65$.

Sheldon, K. M., \& Kasser, T. (1995). Coherence and congruence: Two aspects of personality integration. Journal of Personality and Social Psychology, 68, 531-543. 
Sheldon, K. M., Ryan, R. M., Deci, E. L., \& Kasser, T. (2004). The independent effects of goal contents and motives on well-being: It's both what you pursue and why you pursue it. Personality and Social Psychology Bulletin, 30, 475-486.

Soenens, B., \& Vansteenkiste, M. (2005). Antecedents and outcomes of self-determination in 3 life domains: The role of parents' and teachers' autonomy support. Journal of Youth and Adolescence, 34, 589-604.

Stallman, H. M., \& Hurst, C. P. (2011). The factor structure of the frost multidimensional perfectionism scale in university students. Australian Psychologist, 46, 229-236.

Steyer, R., Schwenkmezger, P., Notz, P., \& Eid, M. (1994). Testtheoretische Analysen des Mehrdimensionalen Befindlichkeitsfragebogen (MDBF). Diagnostica.

Strobel, A., Beauducel, A., Debener, S., \& Brocke, B. (2001). Eine deutschsprachige Version des BIS/BAS-Fragebogens von Carver und White. Zeitschrift für Differentielle und diagnostische Psychologie.

Suedfeld, P. (1981). Environmental restriction and "stimulus hunger": Theories and application. In H. I. Day (Ed.), Advances in intrinsic motivation and aesthetics (pp. 71-86). New York: Plenum Press.

Tangney, J. P., Baumeister, R. F., \& Boone, A. L. (2004). High self-control predicts good adjustment, less pathology, better grades, and interpersonal success. Journal of Personality, 72, 271-324.

Thaler, R. H. (1991). Quasi rational economics. New York: Russel Sage Foundation.

Thaler, R. H., \& Shefrin, H. M. (1981). An economic theory of self control. Journal of Political Economy, 89, 392-406. 
Tice, D. M., \& Baumeister, R. F. (1997). Longitudinal study of procrastination, performance, stress, and health: The costs and benefits of dawdling. Psychological Science, 8, 454-458.

Trope, Y., \& Fishbach, A. (2000). Counteractive self-control in overcoming temptation. Journal of Personality and Social Psychology, 79, 493-506.

U.S. Bureau of Labor Statistics (2010). 2010 SOC User Guide: Standard Occupational Classification and Coding Structure. Downloaded from https://www.bls.gov/soc/soc_2010_class_and_coding_structure.pdf

Unsworth, K. L., \& McNeill, I. M. (2017). Increasing pro-environmental behaviors by increasing self-concordance: Testing an intervention. The Journal of Applied Psychology, 102, 881103.

Vallacher, R. R., \& Wegner, D. M. (1989). Levels of personal agency: Individual variation in action identification. Journal of Personality and Social Psychology, 57, 660-671.

Vallerand, R. J., Fortier, M. S., \& Guay, F. (1997). Self-determination and persistence in a reallife setting: toward a motivational model of high school dropout. Journal of Personality and Social Psychology, 72, 1161-1176.

Van den Broeck, A., Vansteenkiste, M., De Witte, H., \& Lens, W. (2008). Explaining the relationships between job characteristics, burnout, and engagement: The role of basic psychological need satisfaction. Work \& Stress, 22, 277-294.

vanDellen, M. R., Hoyle, R. H., \& Miller, R. (2012). The regulatory easy street: Self-regulation below the self-control threshold does not consumer regulatory resources. Personality and Individual Differences, 52, 898-902. 
Vansteenkiste, M., Lens, W., \& Deci, E. L. (2006). Intrinsic versus extrinsic goal contents in self-determination theory: Another look at the quality of academic motivation. Educational Psychologist, 41, 19-31.

Vansteenkiste, M., Mouratidis, A., \& Lens, W. (2010). Detaching reasons from aims: Fair play and well-being in soccer as a function of pursuing performance-approach goals for autonomous or controlling reasons. Journal of Sport and Exercise Psychology, 32, 217242.

Vansteenkiste, M., Simons, J., Lens, W., Sheldon, K. M., \& Deci, E. L. (2004). Motivating learning, performance, and persistence: the synergistic effects of intrinsic goal contents and autonomy-supportive contexts. Journal of Personality and Social Psychology, 87, 246-260.

Viechtbauer, W. (2010). Conducting meta-analyses in R with the metafor package. Journal of Statistical Software, 36, 1-48.

Wang, J., Novemsky, N., Dhar, R., \& Baumeister, R. F. (2010). Trade-offs and depletion in choice. Journal of Marketing Research, 47, 910-919.

Webster, D. M., \& Kruglanski, A. W. (1994). Individual differences in need for cognitive closure. Journal of Personality and Social Psychology, 67, 1049-1062.

Weinstein, N., Przybylski, A. K., \& Ryan, R. M. (2012). The index of autonomous functioning: Development of a scale of human autonomy. Journal of Research in Personality, 46, 397-413.

Werner, K. M., Milyavskaya, M., Foxen-Craft, E., \& Koestner, R. (2016). Some goals just feel easier: Self-concordance leads to goal progress through subjective ease, not effort. Personality and Individual Differences, 96, 237-242. 
Wiese, C. W., Tay, L., Duckworth, A. L., D’Mello, S., Kuykendall, L., Hofmann, W., ..., Vohs, K. D. (2017). Too much of a good thing? Exploring the inverted-U relationship between self-control and happiness. In press at Journal of Personality.

Williams, G. C., \& Deci, E. L. (1996). Internalization of biopsychosocial values by medical students: a test of self-determination theory. Journal of Personality and Social Psychology, 70, 767-779.

Wood, W. \& Neal, D. T. (2007). A new look at habits and the habit-goal interface. Psychological Review, 114, 843-863.

Wrzesniewski, A., Schwartz, B., Cong, X., Kane, M., Omar, A., \& Kolditz, T. (2014). Multiple types of motives don't multiply the motivation of West Point cadets. Proceedings of the National Academy of Sciences, 111, 10990-10995.

Yeager, D. S., \& Bundick, M. J. (2009). The role of purposeful work goals in promoting meaning in life and in schoolwork during adolescence. Journal of Adolescent Research, 24, 423-452.

Yeager, D. S.,Henderson, M. D., Paunesku, D., Walton, G. M., D’Mello, S., Spitzer, B. J., \& Duckworth, A. L. (2014). Boring but important: A self-transcendant purpose for learning fosters academic self-regulation. Journal of Personality and Social Psychology, 107, 559580.

Zhang, Y. \& Fishbach, A. (2010). Counteracting obstacles with optimistic predictions. Journal of Experimental Psychology: General, 139, 16-31. 
Table 1

Means, standard deviations, and correlations between trait self-control, motivations, and drowsiness (Study 1)

\begin{tabular}{|c|c|c|c|c|c|c|c|}
\hline Measure & $M(S D)$ & 1 & 2 & 3 & 4 & 5 & 6 \\
\hline 1. Self-Control & $3.37(.63)$ & - & & & & & \\
\hline 2. Intrinsic & $1.97(.58)$ & $.21 * *$ & - & & & & \\
\hline 3. Identified & $2.26(.69)$ & $.22 * *$ & $.77 * * *$ & - & & & \\
\hline 4. Introjected & $2.36(.70)$ & $-.28 * * *$ & .06 & .11 & - & & \\
\hline 5. Controlled (Social) & $3.01(.59)$ & -.07 & $.14^{*}$ & .07 & $.45 * * *$ & - & \\
\hline 6. Controlled (Deadline) & $2.55(.60)$ & .02 & -.01 & -.06 & $.25 * * *$ & $.58 * * *$ & - \\
\hline 7. Drowsy & $1.95(.62)$ & $-.28 * * *$ & -.13 & $-.20 * *$ & $.18 * * *$ & .01 & .02 \\
\hline
\end{tabular}

Note. Correlations are calculated for person-level average responses. * indicates $p<.05$, ** indicates $p<.01$, and $* * *$ indicates $p<.001$. 
Table 2

Bootstrap estimates for mediation path components and average indirect effect estimate with $95 \%$ CI (Study 1)

\begin{tabular}{lccccc}
\hline & $\mathrm{a}$ & $\mathrm{b}$ & $\mathrm{c}$ & $\mathrm{c}{ }^{\prime}$ & Indirect effect \& 95\% CI \\
\hline Purpose & $0.21^{* *}$ & $0.24^{* * *}$ & $0.53^{* * *}$ & $0.48^{* * * *}$ & $0.05[0.01,0.10]$ \\
SWLS & $0.21 * *$ & $0.28^{*}$ & $0.86^{* * *}$ & $0.80^{* * *}$ & $0.06[0.00,0.14]$ \\
Burnout & $0.21 * *$ & $-7.49^{* * * *}$ & $-3.45 \dagger$ & -1.90 & $-1.55[-2.97,-0.48]$ \\
\hline
\end{tabular}

Note. Results reflect three separate mediation analyses treating trait self-control as the independent variable, autonomous motivation as the mediator, and one of three measures of well-being as the outcome variable. Purpose $=$ Ryff Purpose scale; SWLS = Satisfaction with Life scale; Burnout $=$ Copenhagen Burnout Inventory. Path $a$ refers to the association between trait self-control and autonomous motivation; $b$ to the association between autonomous motivation and the well-being measure; $c$ to the direct association between trait self-control and well-being; and $c$ ' to the direct association when accounting for autonomous motivation as a putative mediator. Bootstrap estimates are based on 1000 iterations. $\dagger p=.075, * p<.05$, ** $p<$ $.01, * * * p<.001$ 


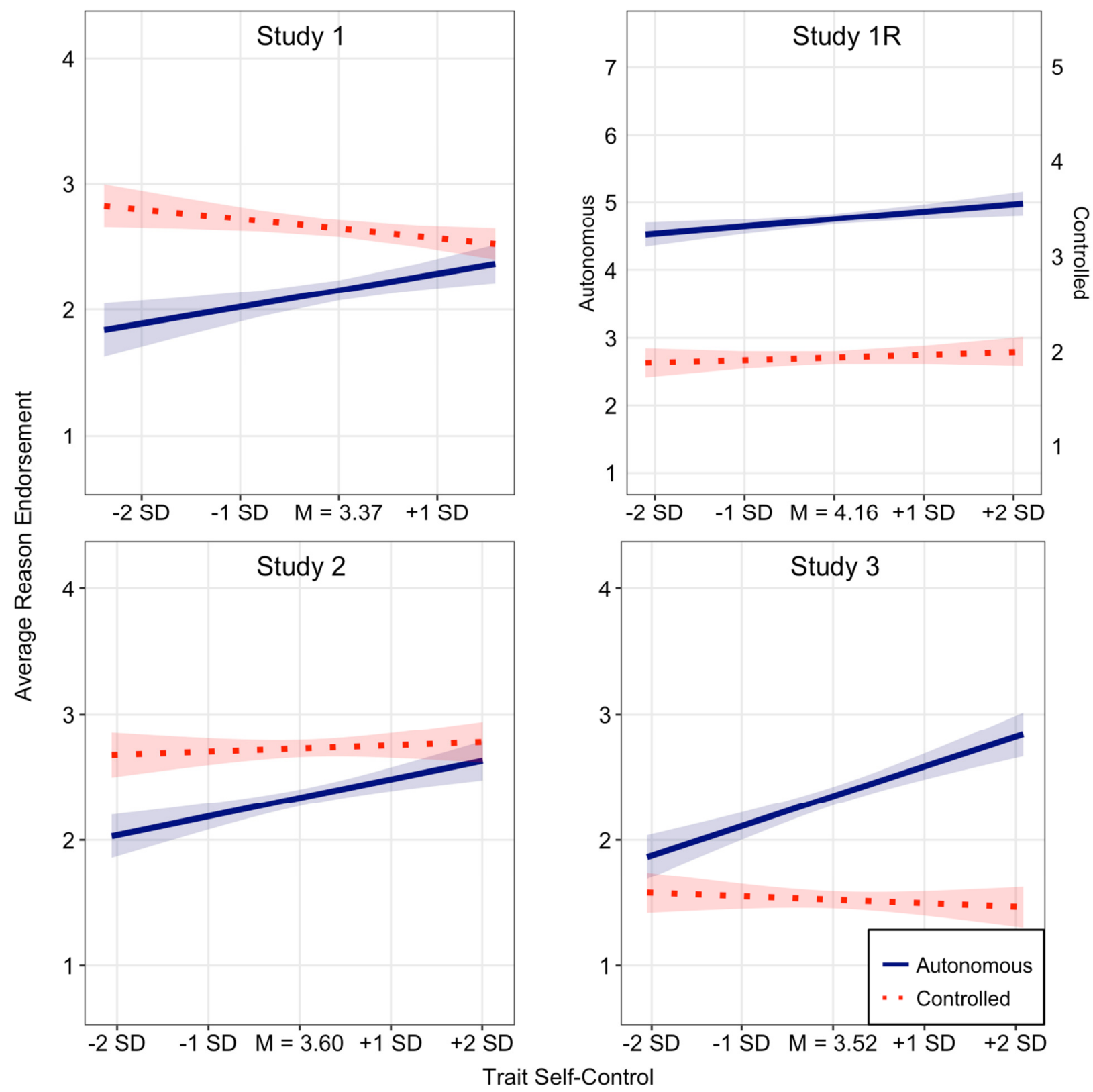

Figure 1. Predicted endorsement level of autonomous and controlled motivation from centered trait self-control across Studies 1-3. Error bands are 95\% CIs. Note that the specific items making up controlled motivation vary across studies as described in the text. In Study 1R, autonomous and controlled motivation were measured on different response scales, reflected by labels on the left and right side of the panel, respectively. See online version for color. 


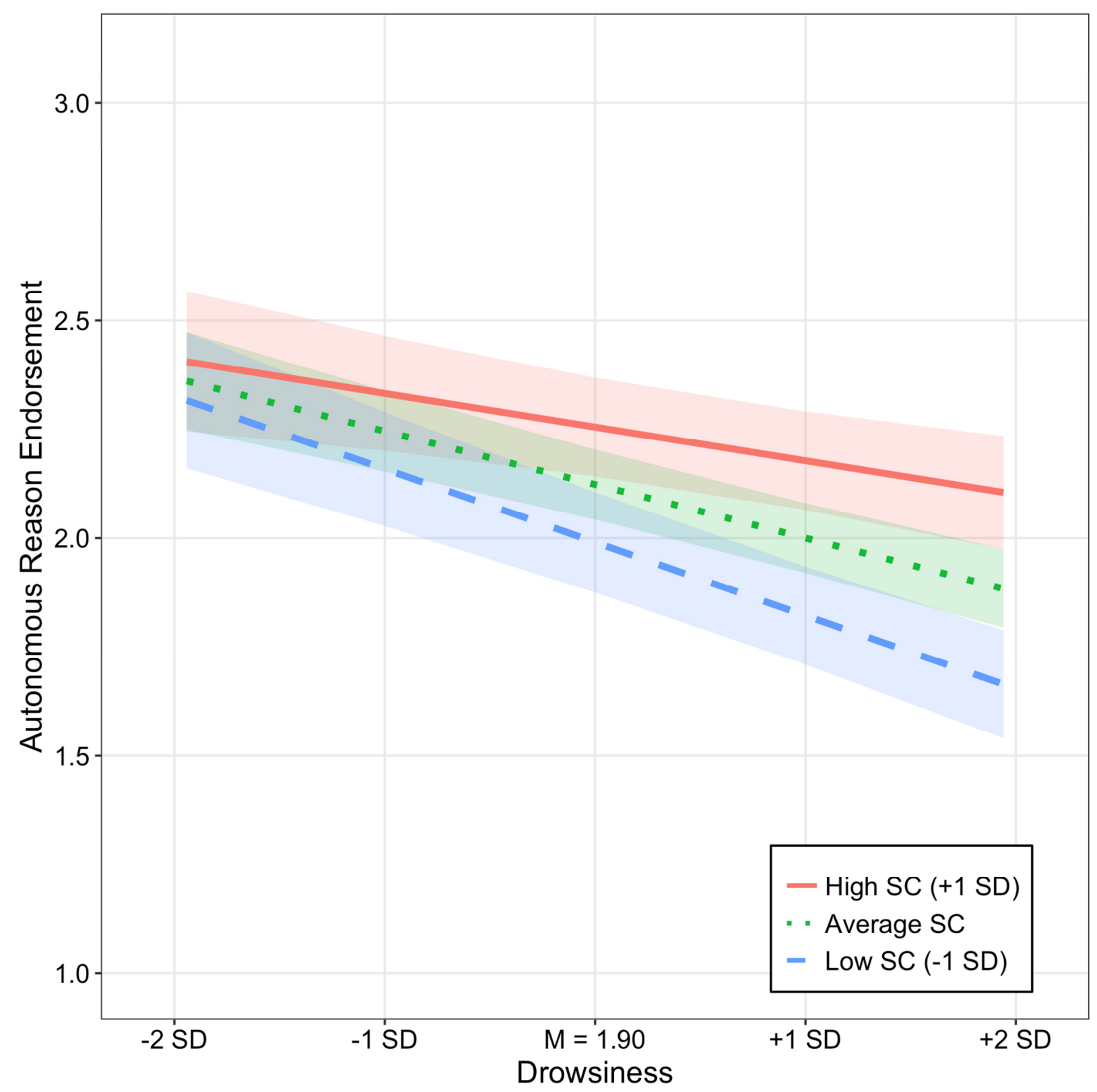

Figure 2. Predicted endorsement level of autonomous motivation from centered drowsiness and trait self-control in Study 1. Error bands are 95\% CIs. See online version for color. 


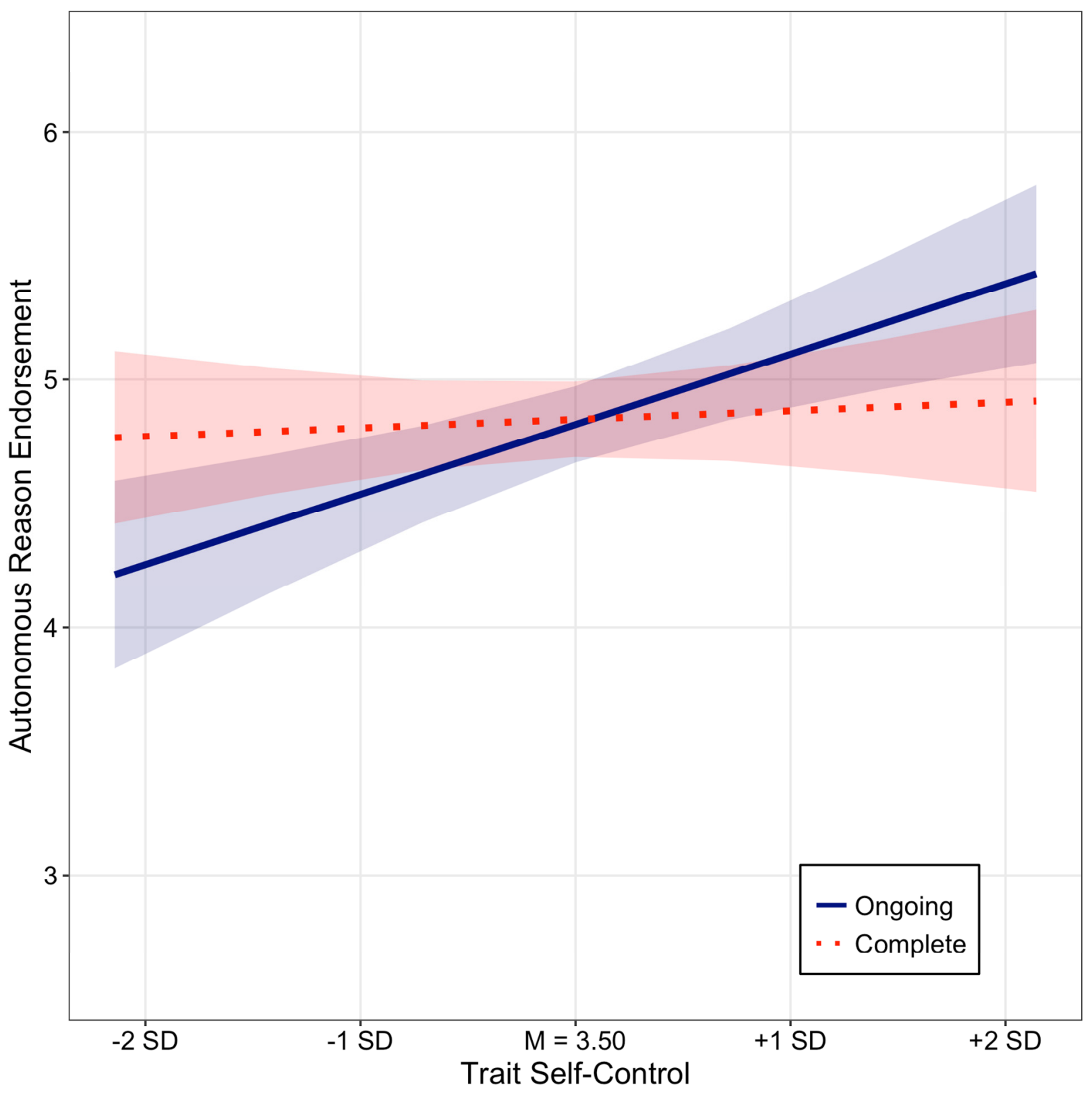

Figure 3. Predicted endorsement level of autonomous motivation from centered trait-self-control and condition in Study 4. Error bands are 95\% CIs. See online version for color. 


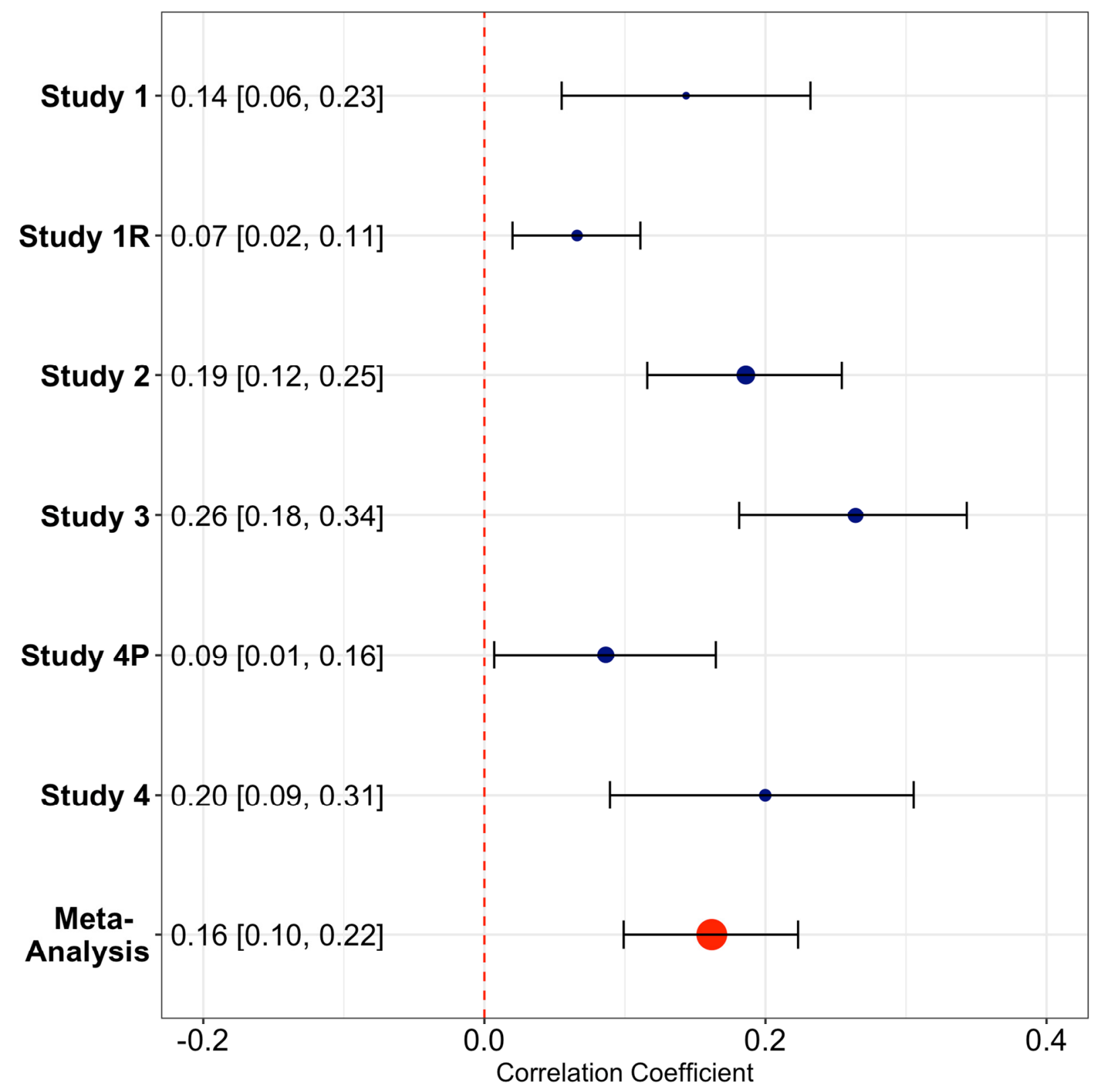

Figure 4. Correlations and 95\% CI estimates for all studies and meta-analytic estimate. See online version for color. 


\section{Footnotes}

${ }^{1}$ Notably, SDT also differentiates the "what" of goal pursuit, such that goals with different content (or aims) can be pursued for different reasons (Elliot \& Thrash, 2001; Elliot \& McGregor, 2001; Vansteenkiste, Lens, \& Deci, 2006; Vansteenkiste, Mouratidis, \& Lens, 2010). For example, one student might have a mastery goal (i.e., success defined by mastering the material) and another student might have a performance goal (i.e., success defined by demonstrating superior understanding; Dweck \& Leggett, 1988; Nicholls, 1984). Each of these goals could be pursued for autonomous or controlled reasons (e.g., pursue mastery because you enjoy it or pursue mastery because of parental pressure). While it is important to acknowledge that reasons and aims are separable (Vansteenkiste et al., 2010), we focus on reasons in the current work.

${ }^{2}$ To date, no other data from this study have been published elsewhere.

${ }^{3}$ Although a strict self-determination definition would exclude "deadline" from this composite, we have included this measure given the correlations between all three variables and the belief that this reflects external pressures. If "social" is the only item used for external regulation, there is no meaningful change in the estimates reported throughout this section.

${ }^{4}$ In the SOM, we introduce time-lagged models that allowed us to ask related but distinct questions about how these processes unfold over time. We tested whether current drowsiness affects subsequent autonomous motivation (and vice versa), and whether trait self-control moderates these quasi-causal processes.

${ }^{5}$ We used the fun item for intrinsic motivation due to its face similarity with our intrinsic motivation item in other studies. However, not surprisingly, fun correlated highly with a subsequent item, "Before beginning with this activity to what extent did you choose the activity 
because you enjoy doing it for its own sake? $(1=$ not at all to $7=$ very much $)$, " person-level $r=$ .82. If, after the fact, we combine them into a two-item composite and re-run the focal analysis, regressing the autonomous-motivation composite on centered trait self-control, we find a weaker, but still positive association, $b=.081,95 \% \mathrm{CI}[.00, .16], \beta=0.05, t=1.97, p=.050$.

${ }^{6}$ We included measures of goal conflict in Studies 1R, 2 and 3 to follow up on findings from the larger procedure associated with Study 1. Because they are not directly related to the hypothesis, we do not address them here. 


\section{Appendix}

\section{Recruitment and Data Collection Plans and Procedures}

\section{Study 1}

For this exploratory study, we determined our sample size based on practical constraints rather than formal power analyses. First, we wanted to get as fine a picture as possible of motivational changes throughout a workday, while balancing participant recruitment, experience, and compliance. We reasoned that "once per hour" over the course of the workday for a week would provide a good representation of the workweek without being too burdensome for participants. This provided a maximum level-1 (moments) sample of 40 responses. Factoring in missed signals, skipped signals, and some "not working" responses, we expected that participants would provide about 5 valid responses per day, for a total of 25 responses per person. Next, we wanted to get as much level-2 power (persons) as possible to allow testing of individual-difference effects. Here, our key constraint was budget. In preparation of the grant proposal that ultimately funded this work, we relied on the heuristic of recruiting at least as many participants as similar studies, and identified Hofmann and colleagues' $(2012 ; N=205)$ work as the most relevant example. We did analyze and report on preliminary results $(N=54)$ in a conference presentation, but trait self-control was not the focus of these analyses, and $N=200$ was a fixed data-collection target throughout.

We recruited via emails and other postings advertising a study about the day-to-day experience of young professionals. We contacted alumni list-servs, social and professional networks, and employed acquaintances; and we posted an advertisement on a popular blog (thetoast.net). Interested individuals learned more about the study from a website describing the general purpose and how to participate. This site in turn directed them to a Qualtrics survey that 
automatically screened for eligibility (based on employment status, age, and possession of a smartphone that could be safely used throughout the workday). We were able to recruit 211 participants. Of those, 15 individuals were excluded from all analyses because they never responded to the ESM signals or completely stopped responding after the first day.

\section{Studies 2 and 3}

To determine our target sample size for these studies, we assumed a relatively small correlation. Because the costs associated with oversampling on MTurk are relatively low (for researchers and participants), we aimed for high power (approximately 90\%). We also wanted to be able to test for the association independently within both counterbalanced order conditions (measuring trait self-control before and after motivation). We therefore aimed for a total sample of at least 500 participants in each study. With 250 per condition, assuming a modest $r=.2$, this target would give us $93.8 \%$ power to detect an effect at significance level of $p<.05$.

We did not have an estimate for how many respondents would pass our hidden screening for the at-work criterion and therefore opened the study on MTurk from 11am - 3pm EST to Eastern time-zone IP addresses and from 11 am - 3 pm PST (2-6 pm EST) for Pacific time-zone IP addresses. Posting in this window increased our chances of fielding a large sample of at-work participants and allowed us to check the number who passed the screening. Our plan was to post for more responses the following day if we had not hit our target ( $N=500$ in each study), but our sample surpassed the target in the first day and we stopped collecting at this stage.

In total, 1,364 individuals consented to be in Study 2 or 3, and 57 of them (4.7\%) stopped responding before the end of the "daily activities" survey that served as the hidden screening procedure. Among the 775 participants who were deemed to be working by the screening survey, and thus branched into Study 2, twenty-seven dropped out before submitting the study (3.5\%; 
their data are excluded). Among the 532 participants who were deemed to be not currently working, and thus branched into Study 3, twenty-four dropped out before submitting the survey (4.5\%; their data are excluded). Trait self-control differed marginally between those who were currently working (Study 2; $M=3.60, S D=.70$ ) and those who were not working (Study 3; $M=$ $3.52, S D=.71), t(1254)=-1.82, p=.07$, but the effect size was very small, $d=.11$, and overall the distributions were fairly similar.

\section{Study 4}

In total, 694 individuals consented to be in Study 4, and 23 of them (3.3\%) stopped responding almost immediately, before being assigned to a condition. Among the 671 participants assigned to a condition, 334 were assigned to the ongoing condition, and 30 dropped out before submitting the study (9.0\%; their data are excluded). Among the 337 participants assigned to the complete condition, 26 dropped out before submitting the survey $(7.8 \%$; their data are excluded). Trait self-control differed marginally between those in the ongoing $(M=$ $3.54, S D=.69)$ versus complete condition $(M=3.44, S D=.70), t(613)=1.69, p=.09$, but the effect size was small, $d=.14$, and the distributions were fairly similar. Importantly, the variance in trait self-control was similar across conditions, suggesting there was equal opportunity to detect an association between it and autonomous motivation in both conditions. 